\title{
Cross-word morphologically conditioned scalar tone shift in Guébie
}

\author{
Hannah Sande ${ }^{1}$
}

Received: 21 September 2017 / Accepted: 8 June 2018 / Published online: 28 June 2018

(C) The Author(s) 2018

\begin{abstract}
This paper presents data bearing on two key issues in morphophonological theory: 1) the domain of phonological evaluation, and 2) the item- versus processmorphology debate. I present data from Guébie (Kru) [Côte d'Ivoire] showing that imperfective aspect is exponed by a scalar shift in surface tone, which can affect either the tone of the inflected verb, or the subject noun phrase. There are four tone heights in Guébie, and the first syllable of a verb can underlyingly be associated with any of the four tones. In imperfective contexts only, that initial verb tone lowers one step on the four-tone scale. If the tone of the verb is already low, the final tone of the subject raises one step instead. This paper demonstrates that in order to account for the cross-word tonal effects of the imperfective morpheme, phonological evaluation must scope over more than one word at a time; specifically, it must scope over a syntactic phase. Additionally, I show that with phonological constraint rankings sensitive to morphosyntactic construction, no abstract phonological underlying form of the imperfective morpheme is necessary.
\end{abstract}

Keywords Scalar tone - Tonal morphology · Process morphology ·

Morphology-phonology interface · Underlying representations · Cophonology theory $\cdot$ Distributed morphology

\section{Introduction}

The primary concern of this study is how to best represent morphological categories that are exponed solely by phonological alternations to a root or stem. In Guébie (ISO: gie), a Kru language spoken in Southwest Côte d'Ivoire, imperfective aspect is

H. Sande

hannah.sande@georgetown.edu

1 Department of Linguistics, Georgetown University, 1421 37th Street NW, Poulton Hall 240,

Washington, DC 20057-1051, USA 
exponed by a scalar shift in tone, which can surface either on the verb root or on the immediately preceding subject. The imperfective morpheme has no segmental exponent, nor a single suprasegmental realization. Instead, we see a tonal interaction between subject and verb that is absent in other contexts. This paper addresses both the scalar aspect of the tone shift, and the locality of the tonal exponent. While no single underlying representation of the imperfective morpheme explains its multiple possible surface realizations, an alternative model is proposed combining phase-based application of morphology and phonology (Marvin 2002; Newell 2008; Pak 2008; Embick 2010; Jenks and Rose 2015; Shwayder 2015; Kastner 2018) with morphemespecific constraints rankings as in Cophonology Theory (Orgun 1996; Inkelas et al. 1997; Anttila 2002; Inkelas and Zoll 2005, 2007).

The scalar tone shift in Guébie presents a particularly interesting challenge for theories of morphophonology, in that the exponent of a single morpheme, the imperfective aspect, is exponed on either the inflected verb, or on the immediately preceding subject noun phrase, depending on the underlying tone of the verb. This crossword exponence requires phonological evaluation of more than one word at a time. I present such a model in this paper.

The scalar tone shift discussed here is one example of a morphologically conditioned phonological alternation, which I take to include any alternation that is not fully general in a language, but occurs in a particular morphological environment or set of environments. In some cases, these phonological alternations co-occur with an overt segmental affix or clitic. In other cases, like the Guébie imperfective tone shift, a phonological alternation takes place in a root or stem without the addition of segmental material. I refer to the latter case as process morphology.

Two central questions surround the theoretical status of process morphology. The first is whether process morphology should be modeled in the same way as morphologically conditioned phonology more generally. On this account I follow Inkelas (2008, 2014), who shows that both process morphology and morphologically conditioned phonology can be modeled in the same way: with construction-specific grammars, or cophonologies. The second question is whether morphologically conditioned phonology and process morphology are best represented with or without underlying phonological items. Sections 1.1 and 1.2 delve deeper into the theoretical significance of these questions, and the latter question is a focus of this paper.

\subsection{Process morphology and morphologically conditioned phonology}

Morphosyntactically conditioned phonology involves phonological allomorphy triggered in particular morphosyntactic contexts. Sometimes, conditioned phonological alternations are accompanied by a segmental affix, clitic, or a compounding or reduplication strategy. I use the term morphologically conditioned phonology to refer to a phonological alternation that occurs together with a segmental exponent, to the exclusion of non-concatenative or process morphology. For example, in Hausa (Chadic), intensive adjectives and pluractional verbs are marked with prefixing reduplication; in the same context, stem initial consonants undergo gemination (Newman 2000, 16, 47, 234-235, 365, 425). 
(1)

Hausa gemination in prefixing reduplication contexts

\begin{tabular}{|c|c|c|c|}
\hline & Verb & Pluractional & Gloss \\
\hline a. & búga: & búbbúgà: & 'beat' \\
\hline b. & dánnè: & dáddàné & 'press down, oppress' \\
\hline c. & $\mathrm{g}^{j}$ àrú & $\mathrm{g}^{j}$ àgg $^{j}$ àrú & 'be well repaired' \\
\hline d. & bí & bíbbí & 'follow' 1' \\
\hline e. & fá: & 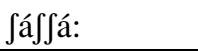 & 'drink' \\
\hline & Adjective & Intensive & Gloss \\
\hline f. & gáutsí: & gàggáutsá: & 'brittle' \\
\hline g. & Kárfi: & Kàkkárfá & 'strong' \\
\hline
\end{tabular}

In Hausa, gemination is a morphologically conditioned phonological alternation, which co-occurs with prefixing reduplication in intensive and pluractional contexts. Root-initial consonant gemination is morphologically conditioned in that it does not occur after every prefix: /tá6à/, 'work', plus the diminutive prefix /dan-/ surfaces as [dan-tá6à], not *[dan-ttá6à].

There are also phonological alternations which occur in particular morphosyntactic contexts without any additional segmental material. I refer to this non-affixal morphology as process morphology. For example, in Alabama (Muskogean), the imperfective aspect is marked by gemination of the onset of the penultimate stem syllable, without additional segmental material (Hardy and Montler 1988:400-401).

\begin{tabular}{llll}
\multicolumn{3}{c}{ Alabama gemination in imperfective contexts } \\
& Base & Imperfective & Gloss \\
\hline a. & balaaka & bállaaka & 'lie down' \\
b. & cokooli & cókkooli & 'sit down' \\
c. & atakaali & atákkaali & 'hang up one object' \\
d. & atakli & áttakli & 'hang more than one object'
\end{tabular}

One could ask whether conditioned phonological alternations which co-occurs with added segmental material, like gemination in Hausa, is fundamentally different from process morphology like gemination in Alabama. Inkelas (2014) carries out an informal survey of morphologically conditioned phonology and process morphology, demonstrating that the two involve the same operations on several levels (Chaps. 2, 3 ). Both morphologically conditioned phonology and process morphology involve a phonological process triggered in a particular morphosyntactic context. What differentiates the two is that morphologically conditioned phonology involves an additional exponent, added segmental material, while process morphology does not. As Inkelas $(2008,2014)$ points out, there is no difference between morphologically conditioned phonology and process morphology in substance (type of operation), scope (the amount of structure to which the operations apply), or layering (the interaction of multiple processes within the same word), thus there is no reason to distinguish between the two in a model of morphophonological interaction. I follow Inkelas's generalization in treating process morphology as a subtype of morphologically conditioned phonology, where there is no meaningful theoretical difference between the two. 
Morphologically conditioned phonological alternations like the Hausa and Alabama examples in Tables 1 and 2 have been modeled in a number of theories which involve multiple distinct phonological grammars present in a single language. These distinct phonological grammars allow for phonological processes like gemination to occur in some morphological contexts, but not others. These Multiple-Grammar Theories (Inkelas 2014, 11), include Lexical Phonology and Morphology (Kiparsky 1982), Stratal OT (Bermúdez-Otero 1999; Kiparsky 2000, 2008), and Cophonology Theory (Orgun 1996; Inkelas et al. 1997; Anttila 2002; Inkelas and Zoll 2005, 2007). Other Single Grammar Theories limit the number of phonological grammars per language to one, but allow rules or constraints to be indexed to particular morphosyntactic contexts. These include the Sound Pattern of English (Chomsky and Halle 1968), as well as parallel Optimality Theory plus indexed constraints (Prince and Smolensky 1993/2004; Itô and Mester 1995a,b; Fukazawa 1998; Itô and Mester 1999; Pater 2007, 2010). Inkelas and Zoll (2007) argue for a multiple-grammar approach over a single-grammar one, eliminating the need for indexed rules or constraints. I follow Inkelas and Zoll in adopting a multiple-grammar approach to morphologically conditioned phonology.

\subsection{Item versus process morphology}

One could imagine an analysis where the phonological processes observed in morphologically conditioned phonological alternations are triggered by the corresponding segmental material. For example, in the Hausa gemination example in Table 1, the presence of the reduplicative prefix itself would trigger gemination of the initial root consonant. On this analysis, it is unclear what would trigger process morphology like gemination in Alabama, which does not co-occur with any additional segmental material. One option is to say that all morphologically conditioned phonological alternations, including process morphology, is triggered by additional phonological material. In the case of Alabama, for example, we could say that there is an underlying floating mora, or perhaps an unspecified consonant, $\mathrm{C}$, which always results in gemination of the onset consonant of the penultimate syllable. In other cases of process morphology, such as subtractive morphology, it is more difficult to determine what type of abstract underlying phonological material could be added to result in the correct surface form.

Much recent literature has indeed adopted the view that all morphology is itembased, meaning that any morphology with phonological exponence is the result of the addition of phonological material (Benua 1997; Alderete 2001; Wolf 2007; Bermúdez-Otero 2012; Gouskova and Linzen 2015; Zimmermann 2013; Trommer and Zimmermann 2014; Köhnlein 2016). This recent work builds on more traditional work in item-based morphology, including Lieber (1980) and Selkirk (1982). Process morphology like truncation, scalar shifts, metathesis, and replacive morphology pose challenges for a purely item-based view of morphology. Hockett (1954) and Anderson (1992) famously raise this debate, both coming down in favor of the need for process morphology without underlying items.

Often, purely item-based analyses of process morphology like truncation involve complex but systematic set of abstract underlying representations. For example, 
Trommer and Zimmermann (2014) analyze subtractive morphology, where input segmental material fails to surface in a particular context, as affixation of a mora. The addition of this mora results in the removal of an input mora on the surface, via constraints referencing autosegmental structure. In Tohono O'Odham, the final segment (mora) of a verb is absent in the perfect (Fitzgerald and Fountain 1995:5-6).

\begin{tabular}{clll}
\multicolumn{3}{c}{ Tohono O'Odham subtractive morphology } \\
& Imperfect & Perfect & Gloss \\
\hline a. & má:k & má: & 'giving' \\
b. & hí:nk & hín & 'barking' \\
c. & híhim & híhi & 'walking (pl)'
\end{tabular}

Trommer and Zimmermann (2014) analyze this subtraction in Tohono O'Odham as affixation of a defective mora in the perfect aspect, which through constraint-based evaluation results in a form that has one fewer mora on the surface than its corresponding input form (4).

Mora affixation: An item-based account of process morphology

(Trommer and Zimmermann 2014, 468, 487)

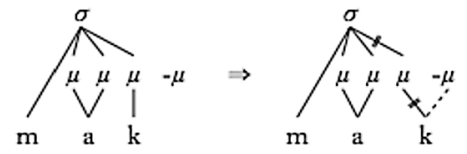

An alternative solution to purely item-based morphology is to allow constraints to drive phonological processes without the addition of abstract underlying items. I propose such a solution throughout this paper, in a model termed Distributed Cophonology Theory, which is based on a modular grammar, where morphological and phonological operations apply at syntactic phase boundaries (as in certain versions of Distributed Morphology such as Embick 2010), and a constraint-based implementation of Cophonology Theory (Orgun 1996; Inkelas et al. 1997; Anttila 2002; Inkelas and Zoll 2005, 2007). While Distributed Morphology is strictly speaking an item-based theory itself, when combined with morpheme-specific cophonologies the result is a model that allows for morphologically conditioned phonology and process morphology to be derived the same way, via constraint-based interaction in particular morphosyntactic environments (cf. Inkelas 2014).

\subsection{Roadmap}

Here we explore a particular case of tonal morphology from Guébie (Kru) [Côte d'Ivoire]. While there are a handful of nominal and verbal affixes in the language, which interact phonologically in interesting ways with each other and with the stems they attach to, much of Guébie morphology is exponed via root-internal tone changes or vowel alternations. Here we focus on the scalar tone shift which expones imperfective aspect. 
Section 2 describes the Guébie imperfective scalar tone shift. ${ }^{1}$ In Sect. 3 I propose a Distributed Cophonology Theory account of the data and discuss the merits of possible alternative analyses. Two other instances of tonal morphology are described in Sect. 4, where the same model used to account for scalar tone is shown to also account for tonal case marking and replacive tone in noun-noun compounds. I conclude in Sect. 5 with a discussion of the implications of the data and model.

\section{Guébie scalar tone shift}

This section examines a pattern of scalar tone shift in Guébie (Kru) [Côte d'Ivoire], which only occurs in imperfective contexts. The imperfective morpheme has no segmental exponent, nor a single suprasegmental realization. Instead, we see a tonal interaction between subject and verb that is absent in other contexts.

Section 2.1 describes a scalar tone shift phenomenon in Guébie, where in the environment of the morphosyntactic imperfective feature, tones on verbs shift down one step on the four-height tone scale. Section 2.2 describes the result of the scalar shift when the verb tone is already low. In such cases, the final tone of the preceding word, the final subject tone, raises one step.

\subsection{Verb tone lowering}

Guébie is a tonal language with four distinct tone heights, marked here with numbers 1-4 where 4 is high. ${ }^{2}$ Here I summarize relevant details of the tonal inventory of the language before describing the scalar tone shift in question. Attested tone melodies on monomorphemic items in Guébie include four level tones $(1,2,3,4)$, along with four falling melodies $(31,32,41,42)$ and three rising melodies $(13,23,24)$, as depicted in (1).

The tones along the vertical axis in Table 1 represent the first tone of a two-tone contour. Those along the horizontal axis are the second tone of a two-tone contour.

Table 1 Attested monomorphemic melodies

\begin{tabular}{cccccc} 
& & \multicolumn{5}{c}{ Tone 2} \\
& & $\mathbf{1}$ & $\mathbf{2}$ & $\mathbf{3}$ & $\mathbf{4}$ \\
& $\mathbf{1}$ & $\checkmark$ & $\emptyset$ & $\checkmark$ & $\emptyset$ \\
& $\mathbf{2}$ & $\emptyset$ & $\checkmark$ & $\checkmark$ & $\checkmark$ \\
Tone 1 & $\mathbf{3}$ & $\checkmark$ & $\checkmark$ & $\checkmark$ & $\emptyset$ \\
& $\mathbf{4}$ & $\checkmark$ & $\checkmark$ & $\emptyset$ & $\checkmark$
\end{tabular}

\footnotetext{
${ }^{1}$ The data presented here comes from a corpus developed out of five years of field work in the Guébie community. Those five years of work include three field trips to Gnagbodougnoa, Côte d'Ivoire between 2014 and 2017, along with eight months of working with a Guébie speaker in the US. Each data point in this paper is labeled with a reference to the corpus entry and corresponding archive file bundle. Labels are of the form SPK_YYYYMMDD, where the initials or anonymous code for the speaker who provided the data is given before the underscore, and the date on which the data was collected is listed after the underscore.

${ }^{2}$ Dots in the tonal notation represent syllable boundaries. Multiple numbers within two dots represent contour tones.
} 
A checkmark marks those contours or level melodies attested in Guébie, a $\emptyset$ marks those that are unattested. Contours unattested on Guébie lexical items include rising tones $12,14,34$, and falling tones 43 and 21 . The 14 and 21 melodies occur in certain derived contexts, and 12 can occur if a tone- 1 root is followed by a tone- 2 suffix. See Sande (2017a) for a thorough description of the tonal system in Guébie, and for more on the distribution of individual tonal melodies across the Guébie lexicon.

Word order in Guébie alternates between SAuxOV and SVO. Auxiliaries mark aspect, polarity, and mood. When an auxiliary is present, there is no inflection on the main verb (5).

SAuxOV: Lexical tone

\section{a. Future}

$\mathrm{e}^{4} \quad \mathrm{ji}^{3} \quad \mathrm{ja}^{31} \quad \underline{\mathrm{li}^{3}}$

1SG.NOM FUT coconuts eat

'I will eat coconuts.'

b. Irrealis

$\mathrm{e}^{4} \quad \mathrm{ka}^{3} \mathrm{ja}^{31} \quad \underline{\mathrm{ii}^{3}}$

1SG.NOM IRR coconuts eat

'I would eat coconuts.'

c. Negative perfective

$\mathrm{e}^{4} \quad \mathrm{la}^{2} \quad \mathrm{ja}^{31} \quad \underline{\mathrm{ii}}^{3}$

1SG.NOM IRR.NEG coconuts eat

'I did not eat coconuts.' (syl_20131024)

However, when there is no auxiliary, the verb surfaces immediately after the subject, and in exactly these cases the verb is inflected for aspect. Nothing can ever intervene between subject and auxiliary or subject and inflected verb (*Subj Adv V O). ${ }^{3}$

Perfective SVO: Lexical tone

$$
\begin{aligned}
& \mathrm{e}^{4} \quad \underline{\mathrm{li}^{3}} \quad \mathrm{fa}^{3}-6 \mathrm{e}^{1} \quad \mathrm{kubə}^{3.1} \\
& \text { 1SG.NOM eat.PFV coconuts-SG yesterday } \\
& \text { 'I ate a coconut yesterday.' (syl_20131024) }
\end{aligned}
$$

Verbs can surface initially in a clause in imperative contexts (7).

$$
\begin{aligned}
& \text { Imperative: Lexical tone } \\
& \quad \frac{\mathrm{li}^{3}}{\text { eat.IMP }} \\
& \text { 'Eat!' (syl_20131024) }
\end{aligned}
$$

In all SAuxOV, SVO, and V constructions in (5), (6), and (7) above, the surface tone on the verb eat is a level tone 3. However, in imperfective SVO contexts, tone on the verb surfaces one step lower on the four-height tone scale (8).

\footnotetext{
${ }^{3}$ The inflectional position in Guébie is not a second-position or Wackernagel phenomenon. Rather, it shows all of the properties of being an inflectional, T, position that requires a DP in its specifier position. For more on the syntactic structure responsible for these two surface word orders, see Sande (2017a, Sect. 4.3.1).
} 
(8) Imperfective SVO: Tone one step lower
$\mathrm{e}^{4} \quad \underline{\mathrm{li}^{2}} \quad \mathrm{ja}^{31} \quad$ koko $^{4.4}$
1SG.NOM eat.IPFV coconuts everyday
'I eat coconuts everyday.' (syl_20131024)

There is no segmental exponent of the imperfective morpheme. Perfective and imperfective clauses, the only SVO constructions, are identical segmentally and syntactically, except for the tone on the verb. Thus, we see minimal tone pairs as in (9).

(9) Scalar tone minimal pairs

a. Perfective: Lexical tone

$\mathrm{e}^{4} \quad \underline{\mathrm{i}^{3}} \quad \mathrm{fa}^{3}-6 \partial^{1}$

1SG.NOM eat.PFV coconuts-SG

'I ate a coconut.'

b. $\frac{\text { Imperfective: One step lower }}{\mathrm{e}^{4} \quad \mathrm{li}^{2}}$

1SG.NOM eat.IPFV coconuts-SG

'I am eating a coconut.' (oli_20160801)

This scalar tone shift in imperfective contexts is an example of a tone change triggered in a particular morphosyntactic environment. Similar morphological tonal override patterns are found elsewhere in Guébie and are common in other West African languages. For an overview of such patterns across West Africa, and more broadly, see Hyman (2018) and Rolle (in preparation).

In the case of a contour tone on a verb, only the first tone level is lowered (10).

(10) Only the first tone of a contour lowers
a. faci $^{23.1} \mathrm{pa}^{31} \quad$ golo $^{3.3}$
Jachi flip.PFV boat
'Jachi flipped the boat.'
b. faci $^{23.1} \mathrm{pa}^{21} \quad$ gols $^{3.3}$
Jachi flip.IPFV boat
'Jachi flips the boat.' (syl_20140123)
c. $\mathrm{e}^{4} \quad \underline{\mathrm{na}^{42}}$
1SG.NOM say.PFV
'I say.'
d. $\quad \mathrm{e}^{4} \quad \frac{\mathrm{na}^{32}\left(* \mathrm{na}^{31}\right)}{\text { 1SG.NOM say.IPFV }}$
'I said.' (syl_20131024)

Similarly, only the first tone level of a polysyllabic verb lowers in imperfective contexts (11).

(11) Only the first syllable lowers
a. $\mathrm{ju}^{4} \mathrm{gbala}^{3.4} \mathrm{si}^{3}$
boy climb.PFV trees
'A boy climbed trees.' 


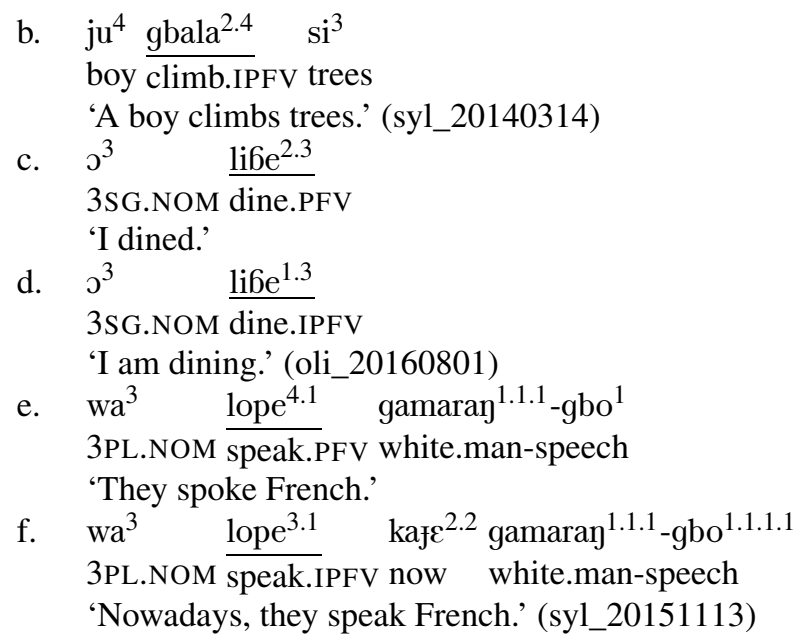

When a polysyllabic verb begins with a level tone melody across multiple syllables, tone on all of those syllables lowers (12). This suggests that there is only a single underlying tone in verbs like bala ${ }^{2.2}$ in (12), which is associated with two tone-bearing units, as per the Obligatory Contour Principle (Leben 1973). That single tone is lowered in imperfective contexts, resulting in both tone-bearing units surfacing with tone one step lower than in the perfective.

The OCP in Guébie scalar tone shift
a. $\mathrm{a}^{2} \quad \mathrm{ka}^{3} \operatorname{dibo}^{3.1}-\partial^{2} \quad \underline{\text { bala }^{2.2}}$
1PL.NOM IRR plantain-PL harvest
'We would harvest plantains.'
b. $\mathrm{a}^{2} \quad$ bala $^{1.1} \quad \operatorname{dibo}^{3.1}-\partial^{2}$
1PL.NOM harvest.IPFV plantain-PL
'We harvest plantains.' (syl_20140314)

While there are very few verbs longer than two syllables in Guébie, all polysyllabic verbs pattern like disyllabic ones, where only the first level tone melody of a verb lowers in imperfective contexts. Given the data in (10), (11), and (12) we can restate the imperfective scalar tone shift by saying that the first tone level of a verbal tone melody surfaces one step lower in imperfective contexts than elsewhere (Table 2).

A more extensive list of underlying (perfective) and imperfective verb forms is given in Table 3. The following section discusses the surface realization of imperfective scalar tone shift when the verb has a lexical low tone.

Table 2 Imperfective scalar tone shift

\begin{tabular}{ll}
\hline Lexical tone & Imperfective tone \\
\hline 4 & 3 \\
3 & 2 \\
2 & 1 \\
1 & 1 \\
\hline
\end{tabular}


Table 3 Perfective and imperfective verb forms

\begin{tabular}{|c|c|c|c|c|}
\hline & & Perfective & Imperfective & Gloss \\
\hline \multirow[t]{10}{*}{ Levels } & a. & $\mathrm{gba}^{4}$ & $\mathrm{gba}^{3}$ & 'bark' \\
\hline & b. & gbala $^{4.4}$ & gbala $^{3.3}$ & ‘sew’ \\
\hline & c. & $6 \approx 1 v^{4.4}$ & $6 \mho 1 \mho^{3.3}$ & 'crawl' \\
\hline & d. & bala ${ }^{3.3}$ & bala $^{2.2}$ & 'hit' \\
\hline & e. & gbete $^{3.3}$ & gbete $^{2.2}$ & 'boil' \\
\hline & f. & $\mathrm{wi}^{3}$ & $\mathrm{wi}^{2}$ & 'cry' \\
\hline & g. & $6 \mathrm{ili}^{3.3}$ & $6 \mathrm{inli}^{2.2}$ & 'sing' \\
\hline & h. & $\mathrm{ji}^{3}$ & $\mathrm{ji}^{2}$ & 'come' \\
\hline & i. & $1 \mathrm{i}^{3}$ & $\mathrm{li}^{2}$ & 'eat' \\
\hline & $\mathrm{j}$. & $\mathrm{pa}^{2}$ & $\mathrm{pa}^{1}$ & 'tell' \\
\hline \multirow[t]{8}{*}{ Contours } & $\mathrm{k}$. & lope 4.1 & lope $e^{3.1}$ & 'speak' \\
\hline & 1. & $\mathrm{pra}^{3.1}$ & $\mathrm{pra}^{2.1}$ & 'buy' \\
\hline & $\mathrm{m}$. & $\operatorname{cie}^{4.2}$ & ci.e $e^{32}$ & 'learn' \\
\hline & $\mathrm{n}$ & $\mathrm{na}^{42}$ & $\mathrm{na}^{32}$ & 'say' \\
\hline & o. & jiri $^{2.3}$ & jiri $^{1.3}$ & 'steal' \\
\hline & p. & gale 2.3 & gale $\varepsilon^{1.3}$ & 'give birth' \\
\hline & q. & gbala $^{2.4}$ & gbala $^{1.4}$ & 'rise' \\
\hline & r. & gbala $^{3.4}$ & gbala $^{2.4}$ & 'climb' \\
\hline \multirow[t]{3}{*}{ Non-alternating } & s. & gala $^{1.1}$ & gala $^{1.1}$ & 'perch' \\
\hline & t. & $\mathrm{ci}^{1}$ & $\mathrm{ci}^{1}$ & 'start' \\
\hline & u. & $\mathrm{pa}^{1}$ & $\mathrm{pa}^{1}$ & 'run' \\
\hline
\end{tabular}

\subsection{Subject tone raising}

Given the consistent one-step lowering process in imperfective contexts discussed in the previous section, we might expect a verb with a lexical low tone (tone 1) to lower further in the imperfective, to a super-low tone, 0. Instead, low-tone verbs retain their low tone, tone 1. There is no surface instance of a super-low tone in Guébie, and the imperfective is no exception. However, we also do not see complete neutralization between perfective and imperfective low-toned verbs; instead, contrast is maintained by raising the final tone of the subject when the verb is already low. The final word of the subject that undergoes tone change is underlined in the following examples.

(13) Subject pronoun tone raising when verb tone is low
a. $\varepsilon^{3} \quad 60^{1}$
3SG.NOM wither.PFV
'It withered.'
b. $\varepsilon^{4} \quad 60^{1}$
3SG.NOM wither.IPFV
'It withers.'


Subject tone raising occurs when the subject DP contains only a pronoun, as in (13), above, but also when the subject DP contains a proper name or full DP (14).

(14) Subject proper noun tone raising when verb tone is low
a. $\frac{\text { faci }^{23.1}}{\text { Djatchi runPFV }} \mathrm{pa}^{1}$
'Djatchi ran.'
b. faci $^{23.2} \mathrm{pa}^{1}$
Djatchi run.IPFV
'Djatchi runs.'

When the subject DP contains a relative clause, the relative clause marker is the final word in the subject, and is the target of tone raising (15).

(15) Subject relative clause tone raising when verb tone is low
a. $\left[\mathrm{ju}^{4} \mathrm{e}^{4} \mathrm{ji}^{2} \quad \underline{\mathrm{ne}^{2}}\right] \mathrm{pa}^{1}$
boy I know REL run.PFV
'The boy that I know ran.'
boy I know REL run.IPFV
'The boy that I know runs.' (oli_20160801)
b. $\quad\left[\mathrm{ju}^{4} \mathrm{e}^{4} \mathrm{ji}^{2} \quad \mathrm{ne}^{3}\right] \mathrm{pa}^{1}$

The low tone, 1 , on the verbs 'wither, run' in (13a, 14a, 15a) does not lower in imperfective contexts but we see a change in the final subject tone between perfective and imperfective, $(13 \mathrm{~b}, 14 \mathrm{~b}, 15 \mathrm{~b})$. Here we are seeing an aspectual feature, imperfective, [IPFV], exponed on the subject of the sentence, whether that subject is a pronoun or full noun phrase.

It is quite common for subject pronouns to be inflected for tense and aspect in West Africa, especially in South Mande languages, which border Kru languages in Côte d'Ivoire and Liberia (Vydrine 2006, 51); however, it is quite uncommon for non-pronominal subjects in the area to show this effect. In Guébie, all subjects, including pronouns, proper nouns, and full noun phrases, undergo final-tone raising in imperfective contexts if the verb tone is underlyingly low.

This scalar subject raising occurs even when the result is a super-high tone, tone 5 , which is not found elsewhere in the language (16). This is particularly surprising given that a low-toned verb cannot lower to super-low, but a super-high tone surfaces in subject-raising contexts.

(16) Contrast is maintained even when it results in a super-high tone
a. $\mathrm{e}^{4} \quad \mathrm{pa}^{1}$
1SG.NOM run.PFV
'I ran.'
1SG.NOM run.IPFV
'I run.' (syl_20140314)
b. $\underline{\mathrm{e}}^{5} \quad \mathrm{pa}^{1}$

Before a low-toned verb, tone 1, we get the subject tonal alternations in Table 4. 
Table 4 Subject tone alternations

\begin{tabular}{ll}
\hline Lexical subject tone & Raised subject tone \\
\hline 4 & 5 \\
3 & 4 \\
2 & 3 \\
1 & 2 \\
\hline
\end{tabular}

The scalar shift in Guébie, where the first tone of a verb lowers one step if possible, and if not the subject tone raises one step, represents a novel type of scale crosslinguistically. Mortensen (2006) presents a typology of synchronic scalar phonological phenomena, introducing the five possible types of scales shown in Figs. 1-5.

Fig. 1 Identity mapping (from Mortensen 2006, 56-67)

$$
\text { AD } B D C D C D
$$

Any faithful input-to-output mapping is an identity mapping, represented above. Figure 2 shows a neutralization scale, where all elements on the scale surface in the same way, thus losing input contrast.

Fig. 2 Neutralization

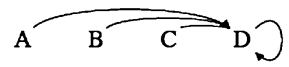

Figure 3 shows a scalar shift where element A on the scale becomes B, B becomes $\mathrm{C}, \mathrm{C}$ becomes $\mathrm{D}$, and $\mathrm{D}$ bounces back to $\mathrm{C}$.

Fig. 3 Bounceback

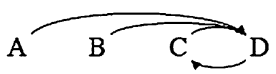

Figure 4 shows a chain shift of the type commonly seen diachronically (e.g. the Great Vowel Shift). In a synchronic chain shift, there is an environment in which input $\mathrm{A}$ becomes $\mathrm{B}$ and $\mathrm{B}$ becomes $\mathrm{C}$, while $\mathrm{C}$ and $\mathrm{D}$ both neutralize to $\mathrm{D}$.

Fig. 4 Chain shift

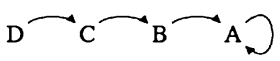

In a circle chain, Fig. 5, we see a chain shift where the final element of the scale surfaces as the initial element of the scale, thus maintaining surface contrast among all elements.

Fig. 5 Circle chain

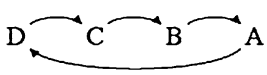

The verb-tone lowering scalar shift in Guébie is similar to the chain shift in Fig. 4; however, there is a second dimension to the chain shift in Guébie, where upon reaching the end of the scale, a scalar chain shift in the opposite direction is triggered on a 
nearby word. For more work on synchronic chain shifts, see Foley (1970), Kirchner (1996), Gnanadesikan (1997) and Łubowicz (2011).

The scalar tone shift in Guébie affects the difference in scalar value between two words or morphemes. That is, this tonal shift affects the difference in tone height between the subject and verb, where the difference increases by one between the perfective and imperfective. This consistent and phonologically productive tone change is represented formulaically in Table 5, where FST stands for Final Subject Tone, and IVT stands for Initial Verb Tone. $n$ represents some number, namely, the difference in height between subject and verb tone in perfective contexts.

It is not always the case that the subject and verb tones are further from each other in the imperfective than in the perfective. For example, a subject with final underlying tone 3 followed by a verb with underlying tone 4 will surface as 3 followed by 3 in the imperfective, where subject and verb have the same tone. The difference between perfective and imperfective then is not that subject and verb are assimilating to or dissimilating from each other. Rather, a rising melody across the subject-verb juncture becomes less rising, a flat melody becomes falling, and a falling melody becomes a steeper falling melody, as shown in Table 6, where alternations for all possible tone levels following a tone-2 subject are shown. All tonal relationships between subject and verb in the perfective surface more like a falling tone in the imperfective, while only shifting one step on the tonal scale.

We can summarize the imperfective scalar tone shift in Guébie in this way: the first tone height of a verb surfaces one step lower in the imperfective than elsewhere, unless the verb is already low, in which case the final subject tone raises one step. The imperfective shift could be said to show more of a pitch drop than the perfective or underlying counterpart; that is, the subject is relationally one step higher compared to the verb in the imperfective than it was in the input.

This scalar tone shift is situated within the larger context of Guébie grammatical tone phenomena. I provide an analysis of this particular scalar shift in Sect. 3, where we see that this pattern bears directly on questions of the locality of phonological application, and the representation of tonal morphemes. In Sect. 4 we see that the proposed analysis extends to other instances of tonal and non-tonal morphology in Guébie.

Table 5 Consistent arithmetic relationship between perfective and imperfective

Table 6 Tone shift patterns for a subject with tone 2

\begin{tabular}{ll}
\hline Perfective & Imperfective \\
\hline FST - IVT $=n$ & FST - IVT $=n+1$ \\
\hline
\end{tabular}

\begin{tabular}{llll}
\hline & Pfv & Ipfv & Subj/Verb tone difference \\
\hline a. & 24 & 23 & Decrease \\
b. & 23 & 22 & Decrease (to equal) \\
c. & 22 & 21 & Increase \\
d. & 21 & 31 & Increase \\
\hline
\end{tabular}




\section{Scalar shift in Distributed Cophonology Theory}

The data presented in Sect. 2 bear on questions at the morphology/phonology interface. The Guébie imperfective morpheme is exponed via a relative scalar tone shift, and affects the surface realization of multiple words. The scalar, cross-word nature of this tonal shift pushes the boundaries of the kinds of phonological processes we expect to see across languages, and has direct implications for what a model of morphophonology must be able to do. I argue there that the crossword effects of the imperfective tone shift are evidence that phonological evaluation must scope over more than one word at a time. I also argue in favor of abstract phonological scales, and constraints that reference those scales, in order to account for the Guébie scalar tone shift, and other phonological scales across languages.

This section presents an analysis of the morphology/phonology interface in Guébie, relying on morphological and phonological evaluation at syntactic phase boundaries, and morpheme-specific phonological grammars or cophonologies. I assume a modular grammar, where morphology and phonology operate on the output of syntax. Section 3.1 discusses the morphological component, and Sect. 3.2 the phonological component. Section 3.3 considers possible alternative analyses, concluding that Guébie imperfective scalar tone is best modeled with no underlying representation, but with an imperfective-specific cophonology.

\subsection{The morphological component}

Here we see how a novel combination of existing theoretical tools can account for the cross-word imperfective scalar tone shift in Guébie. This model combines aspects of Distributed Morphology (DM) (Halle and Marantz 1993, 1994), namely late insertion of Vocabulary items and phase-based spell-out, with multiple subgrammars of constraint-based evaluation (Lightner 1965; Kiparsky 1982; Orgun 1996; Inkelas et al. 1997; Itô and Mester 1999; Kiparsky 2000; Anttila 2002; Inkelas and Zoll 2005, 2007; Kiparsky 2008). The particular implementation of subgrammars adopted here has features of Cophonology Theory (Orgun 1996; Inkelas et al. 1997; Anttila 2002; Inkelas and Zoll 2005, 2007) and Indexed Constraint Theory (Itô and Mester 1995a,b; Fukazawa 1998; Itô and Mester 1999; Pater 2007, 2010). I begin by describing my assumptions about the morphological component of the grammar, then discuss the output of morphology which I assume is the input to the phonological component.

Like DM, the model of the morphology/phonology interface presented here assumes that syntactic structure is the input to the morphological component. The syntactic structure of a regular transitive verb in Guébie is given in (17), where the verb has head-moved through Voice to $\mathrm{T}$, the inflectional position. $\mathrm{T}$ is the position of auxiliaries, when they surface, and of inflected verbs when there is no auxiliary present. Nothing can ever intervene between the subject and the inflectional position (Sande 2017a). The aspectual features IPFV and PFV are introduced in T, and neither is associated with a Vocabulary item (underlying form) to be inserted. A hierarchical structure of the type in (17) is assumed to be both the output of syntax and the input to morphology. 
The input to morphology

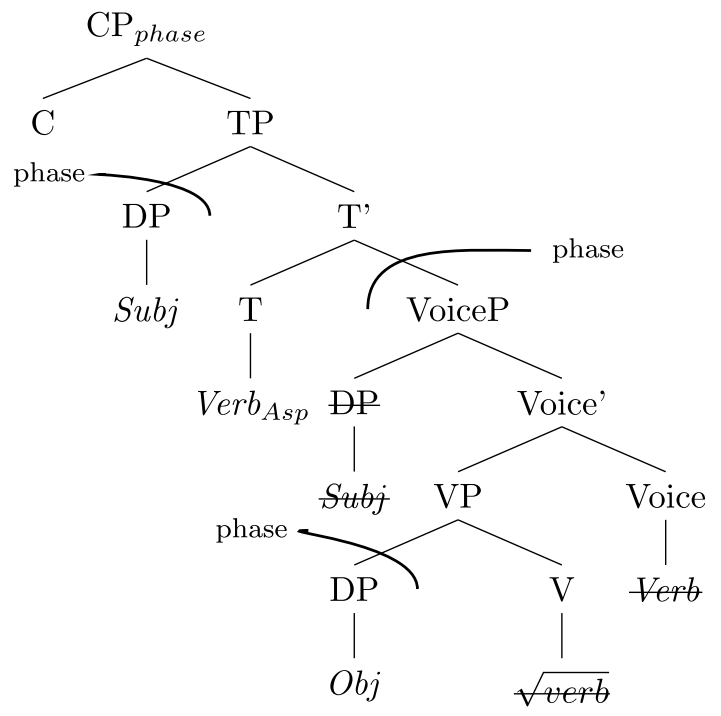

Following DM, I assume that morphological operations apply to the hierarchical syntactic structure in (17). For more on the catalog of operations that apply during the morphological component, see Embick and Noyer (2001, 2007). Here I discuss only those morphological operations relevant in accounting for Guébie scalar tone shift, including Vocabulary insertion and linearization.

I assume that the syntactic structure in (17) is spelled out, or sent to the morphological component, in small chunks. There are at least three current proposals in the Distributed Morphology literature for how often syntactic structure is spelled out, and which syntactic nodes determine that spell-out. The first, which I adopt here, is that morphophonological spell-out occurs at syntactic phase boundaries (Marvin 2002; Newell 2008; Pak 2008; Embick 2010; Jenks and Rose 2015; Shwayder 2015; Kastner 2018). The second is that morphological operations apply cyclically at every instance of syntactic merge (Bobaljik 2000; Matushansky 2006). The third is that morphophonological domains do not align in any predictable way with syntactic domains (cf. Deal and Wolf 2017).

I adopt spell-out-by-phase, where relevant phases are at least DP, VoiceP, and CP, as marked with phase boundaries in (17). ${ }^{4}$

The benefit of spell-out at each phase boundary is that it naturally accounts for the cross-word effects of the imperfective scalar tone shift. The subject and verb are spelled out together, within the same phase, and are thus evaluated by the phonological component simultaneously. Everything hierarchically below $\mathrm{T}$ is spelled out in the Voice phase and the subject DP is spelled out in its own DP phase. After each phase is spelled out, the phonologically optimal output string remains in the derivation and is susceptible to subsequent spell-out cycles, but all internal hierarchical structure

\footnotetext{
${ }^{4}$ Note that the data presented here are also consistent with a theory of phases where the highest phrasal projection of categories N, P, A, and V, function as phases (Bošković 2014).
} 
and morpheme boundaries within that phase are lost. For example. The verb in $\mathrm{T}$ is spelled out in the CP phase, which encompasses T, the lower VoiceP, and, crucially, the subject DP. During the point at which the CP is spelled out, the VoiceP and DP have already been phonologized and no longer contain information about their internal structure. However, their phonological content is still manipulable during evaluation of higher phases, unless highly ranked faithfulness constraints prevent them from undergoing change. In this way, morphology and phonology apply to the subject and verb together, during spell-out of the CP phase. This simultaneous phonological evaluation of subject and verb is a necessary feature of any model of Guébie imperfective scalar tone shift, since the process affects the phonological outputs of both subjects and verbs.

Note that the subject, a DP, was previously spelled out as a separate DP phase, but is still manipulable at later instances of spell-out, as per McPherson and Heath's (2016) violable IDENT-PHASE constraints adopted in Sect. 3.2. Violable phase identity is a necessarily weaker version of the notion of phase impenetrability at the morphological and phonological levels (Kramer 2010; d'Alessandro and Scheer 2015; Shwayder 2015). Strict modular phase impenetrability assumes that previously spelled-out material is no longer manipulable by morphological or phonological operations; however, following (McPherson and Heath 2016), I assume that the phonological phase impenetrability condition (P-PIC) is violable. All non-low-toned verbs have multiple possible surface realizations: they can surface with their lexical tone melody, or the initial verb tone can surface one step lower than the lexical tone. One possibility in DM is to say that each verb has multiple Vocabulary entries, one of which is inserted in imperfective contexts, and the other which is inserted elsewhere. However, this requires phonologically predictable imperfective forms to be listed in the lexicon along with the default, non-imperfective form (see Sect. 3.3 for further reason to discount a suppletive analysis). Instead, I propose that there is only one underlying form or Vocabulary item for each verb, unspecified for insertion context. The tonal difference between perfective and imperfective verb forms is determined later, in the phonological component.

Tones in Guébie are represented underlyingly as discrete units, numbers 1-4, which are related to each other in a scalar manner. These tones are associated to tone-bearing units via autosegmental association lines, as in (18).

Autosegmental representations of Guébie tones

$\begin{array}{lllllll}\text { a. } & 3 & \text { b. } & 3 & 1 & \text { c. } & 3 \backslash 1 \\ \text { b a l a } & & \text { b a l a } & & \text { b a }\end{array}$

When a single tone on the tonal tier is associated to more than one tone-bearing unit, as in (18a), the result is a level tone melody across multiple syllables. When multiple tone heights are associated to a single tone-bearing unit, as in (18c), the result is a contour tone. For simplicity, in the remainder of this paper I leave out the autosegmental representations and simply list the tones as superscripts after each word. 
The single Vocabulary entry proposed for the verb 'eat' is given in (19).

$$
\text { Vocabulary entry for the Guébie verb } l i \text {, 'to eat' }
$$

$$
\mathrm{li}^{3} \longleftrightarrow \sqrt{e a t}
$$

Due to its lack of specified insertion context, the Vocabulary entry in (19) will be inserted in both perfective and imperfective contexts. For this reason, perfective and imperfective derivations of the same verb will look almost identical during the morphological component, as shown in (20), where $l i^{3}$ has been inserted into both the perfective and imperfective structures. The only difference between perfective and imperfective derivations of the same verb is the presence of a PFV feature on $\mathrm{T}$ in one case, and an IPFV feature on $\mathrm{T}$ in the other.

Morphological structure after Vocabulary insertion:

Guébie perfective and imperfective $l i$, 'to eat'
a. Perfective 'I ate'
b. Imperfective: 'I eat'
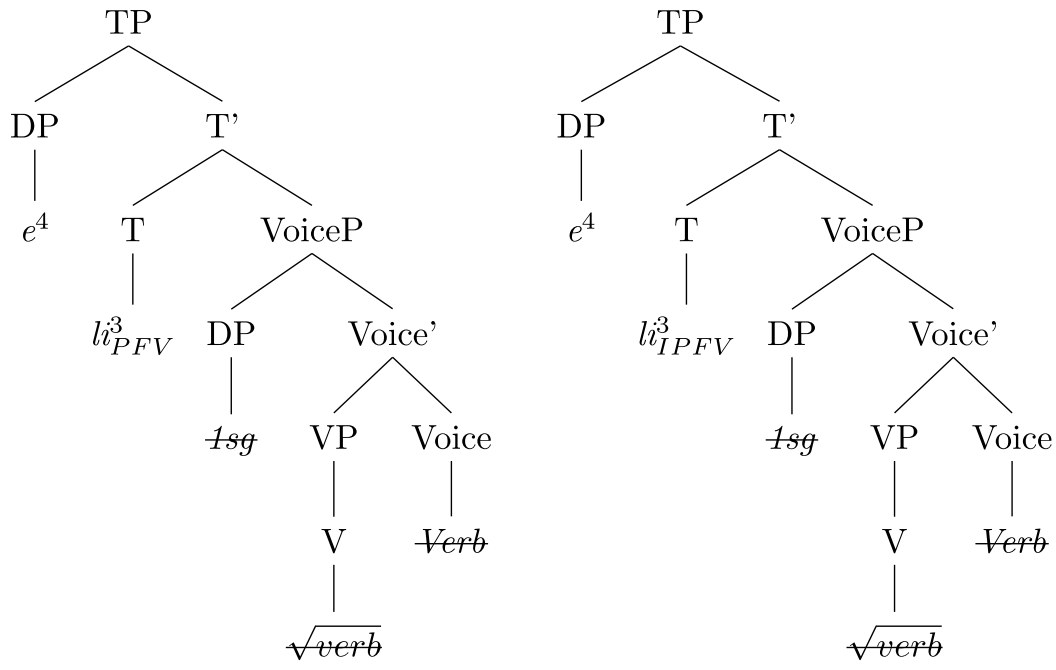

After Vocabulary items are inserted, they are linearized. Even at this point the imperfective and perfective derivations are identical except for the presence of an imperfective or perfective feature (21).

(21) Input to phonology for Guébie perfective and imperfective $l i^{3}$, 'to eat'
a. $/ \mathrm{e}^{4} \mathrm{li}^{3}{ }_{I P F V} /$
b. $/ \mathrm{e}^{4} \mathrm{li}^{3}{ }_{P F V} /$

After linearization, the string of Vocabulary items and morphosyntactic features is evaluated by the phonological grammar. It is during the phonological component that the tone in imperfective contexts undergoes shift. Note that in this model, morphosyntactic features are preserved through morphology, including linearization, and are available to the phonology. ${ }^{5}$ This assumption contradicts Bobaljik's (2000) proposed

${ }^{5}$ In (21), there are other features present in addition to PFV and IPFV, such as $1 \mathrm{SG}$; however, as only the PFV and IPFV features are relevant to the current analysis, I leave out other features in the representation. 
Rewrite Rule, which says that morphosyntactic features are erased upon insertion of Vocabulary items; however, I follow the growing body of literature arguing, directly or indirectly, against the Rewrite Rule (cf. Gribanova and Harizanov 2017; Winchester 2016, and Match Theory constraints which reference hierarchical structure in the phonological component, Selkirk 2011). This architectural feature of the grammar, persistence of morphosyntactic features through to phonology, is also needed to account for phonological agreement and vowel replacement in Guébie, as described in Sande (2016, 2017a,b).

One question that arises at the interface is how to translate the morphosyntactic features of terminal nodes to the phonological component. Sande and Jenks (to appear) propose that partial phonological constraint rankings are inserted via Vocabulary Insertion. According to Sande and Jenks, the imperfective Vocabulary item in Guébie would not include any underlying representation, but a constraint ranking would be inserted during Vocabulary insertion, which overrides the default constraint ranking of the language only during the spell-out cycle containing that morpheme. During spell-out of the CP phase containing the imperfective $\mathrm{T}$ head, the constraint ranking would ensure scalar tone shift. For our purposes, the crucial feature of such an interface model is that the phonological component be able to determine which constraint-based grammars are triggered by which spell-out domains. This interaction between morphology and phonology could be formalized as by Sande and Jenks (to appear), or by assuming that the phonological component can access morphosyntactic features and assign a constraint ranking accordingly.

With the morphological assumptions made in this section, we can account for process morphology using a DM-style morphology plus morpheme-specific constraint rankings. First, spell-out occurs at syntactic phase boundaries, which here include at least VoiceP, DP, and CP. Second, morphosyntactic features must remain in the derivation through morphological operations and be available to the phonology. Third, the phonological component assigns a phonological grammar to each spellout domain based on the morphosyntactic features present in that domain. Note that any theory of morphosyntax in which morphology and phonology apply at syntactic phase boundaries and the phonological grammar is sensitive to morphosyntactic construction could be used to model the same facts. The choice of DM in particular is not crucial, but phase-based spell-out is.

The specific constraints and rankings relevant for scalar tone shift in the imperfective grammar, and for avoiding scalar shift in elsewhere contexts, are discussed in Sect. 3.2.

\subsection{Scalar tone cophonologies}

Here I adopt a constraint-based phonological component which relies on features of both Cophonology Theory (Orgun 1996; Inkelas et al. 1997; Anttila 2002; Inkelas and Zoll 2005, 2007) and Indexed Constraint Theory (Itô and Mester 1995a,b; Fukazawa 1998; Itô and Mester 1999; Pater 2007, 2010). The model adopted here is similar to Cophonology Theory in that multiple distinct morpheme-specific grammars are present in a single language, allowing for scalar shift in imperfective contexts, but not elsewhere. However, we will see that constraints indexed to particular morphemes or categories are still necessary in order for the facts to work out. 
In Distributed Cophonology Theory, morphemes may be associated with a subgrammar, or partial constraint ranking. While not every morpheme triggers a distinct grammar, there may be multiple morpheme-specific grammars in a given language, as well as an 'elsewhere' default grammar. If the phase or spell-out domain being evaluated contains a morpheme for which there is a morpheme-specific phonological grammar, that grammar applies, as in the Guébie imperfective. Otherwise, the 'elsewhere' phonological grammar applies, as in the Guébie perfective. ${ }^{6}$

As discussed in Sect. 3.1, the input to the phonological component is made up of Vocabulary items and morphosyntactic features. The version of Cophonology Theory adopted here assumes that morphosyntactic features are primitive notions that need to be present in the phonology in order for the appropriate cophonological ranking to apply. Here I mark only the relevant features, IPFV and PFV, in the input.

Possible outputs are evaluated by constraints whose ranking is dependent on the morphosyntactic construction in question. For Guébie scalar tone shift, there are two relevant phonological grammars, one triggered by IPFV, which applies to the $\mathrm{CP}$ containing that IPFV feature, and an elsewhere grammar, which applies to all other phases. The phonological constraints specific to the imperfective and elsewhere cophonologies are what determine the tonal difference between perfective and imperfective forms in Guébie ( $\left[\mathrm{e}^{4} \mathrm{li}^{3}\right]$, 'I eat', vs $\left[\mathrm{e}^{4} \mathrm{li}^{2}\right]$, 'I ate').

The model of scalar tone shift proposed here relies on the assumption that phonological constraint rankings can differ with morphosyntactic construction within a single language, and that syntactic units larger than a single word can be evaluated simultaneously. The effect of Guébie scalar tone shift can surface on the subject as in Sect. 2.2, or the adjacent inflected verb, as described in Sect. 2.1, thus the subject and verb must both be present during the phonological evaluation cycle where scalar tone shift takes place. This phrase-level phonological phenomenon bears on questions of syntactic interaction with morphophonology (cf. Embick and Marantz 2008 and Embick 2010:111), showing that phonological evaluation must scope over a domain larger than the individual word.

Subject and verb are simultaneously evaluated in the phonology because they are present in the same spell-out domain (phase). There is no distinction between words and phrases in DM, so there is no need to treat inflectional paradigms within words differently from those that span words within a syntactic phase. All elements that are spelled out together are evaluated together phonologically. For the above reasons, multiword candidates of subject and verb together are evaluated in the tableaux throughout this section.

Section 3.2.1 discusses the constraint ranking relevant to account for scalar tone shift in imperfective contexts. Section 3.2.2 discusses the constraint ranking in the elsewhere grammar.

\subsubsection{The imperfective cophonology}

Beginning with the imperfective phonological grammar in Guébie, we must ensure that the optimal output candidate is tonally different from the input. Thus, we need a

\footnotetext{
${ }^{6}$ See Sande and Jenks (to appear) for how to handle multiple cophonologies triggered within a single phase. This potential complication is not discussed further here.
} 
Table 7 Options for tonal realization of imperfective

\begin{tabular}{lcl}
\hline & Raising & Lowering \\
\hline Subject & $\checkmark$ & - \\
Verb & - & $\checkmark$ \\
\hline
\end{tabular}

constraint motivating the difference between input and output tone. This will take the shape of a tonal anti-identity constraint, similar to Mortensen's (2006) DIFF, Kurisu's (2001) REALIZEMORPH, and Alderete's (2001) Transderivational Antifaithfulness.

There are four possible ways in which a multiword candidate could be tonally unfaithful to the input, represented in Table 7: subject raising, subject lowering, verb raising, verb lowering. However, only two of these four possibilities are attested in Guébie.

While we see two of the four possible tonal antifaithfulness strategies for realizing the imperfective morpheme utilized in Guébie (subject raising and verb lowering), we need to not only ensure that the others (verb tone raising and subject tone lowering) never occur, but also that each of subject tone raising and verb tone lowering occur in the right context. One solution is to make use of the NOHIGHER (faithfulness) and HIGHER (antifaithfulness) constraints (Mortensen 2006).

NoHigher (Mortensen 2006, 14)

For each tone-bearing unit in the output, assign one violation if its associated tone surfaces higher on the tone scale than the corresponding input tone.

\section{Higher (Mortensen 2006, 14)}

For each tone-bearing unit in the output, assign one violation if it does not surface higher on the tone scale than the corresponding input tone.

These two constraints, ranked appropriately with category-specific faithfulness constraints such as IDENT-DP, IDENT-T, could result in tone lowering and raising in the appropriate contexts. For simplicity, we can combine these two constraints into a single PITCHDROP constraint as in (24), which requires tonal antifaithfulness at word boundaries.

\section{PITCHDROP}

For each phonological word, $x$, which immediately follows another phonological word, $y$, assign one violation if the final tone level of $y$ is not relatively higher than the initial tone level of $x$ on the four-tone scale than it was in the input.

\begin{tabular}{cc} 
Input & Output \\
\hline $\mathrm{FST}-\mathrm{IVT}=n$ & $\mathrm{FST}-\mathrm{IVT}=n+1$
\end{tabular}

Like Higher, PitchDrop requires a tonal difference between input and output. Such a constraint could be phrased as antifaithfulness to the input tonal difference between words. With the addition of such a constraint motivating a difference between input and output, we need not also include more general antifaithfulness constraints such as REALIZEMORPH (Kurisu 2001), Transderivational Antifaithfulness (Alderete 2001), or Mortensen's (2006) DIFF. While a more general, say, REALIZE- 
MORPH constraint might be present in the constraint inventory, its effects are vacuous in the presence of the more specific PITCHDROP.

We can assess the value of an antifaithfulness constraint like PITCHDROP by examining other instances of morphologically conditioned scalar changes across languages. As previously mentioned, Mortensen (2006) uses the tonal antifaithfulness constraints HighER, NoHigHER to account for scalar phenomena (including tonal, vocalic, and consonantal alternations) across a number of languages. Outside of Mortensen's scalar typology, in Esimbi (Bantu) the prefix vowel /a-/ surfaces one step lower on the four-vowel-height scale than the following underlying root vowel, as described by Hyman (1988) and discussed by Walker (1997). Another example of a morphosyntactically conditioned tonal alternation comes from Samoan. Yu and Özyildiz (2016) and Yu (2018) describe a particular pitch contour triggered in the environment of an absolutive feature in Samoan. Antifaithfulness constraints and abstract scales can be used to account for Esimbi prefix vowels and Samoan absolutive tone, just as they are used here for Guébie.

The PITCHDROP constraint here, requiring more of a pitch drop in subsequent words in the output than in the input, could also be used to account for downstepping or downdrifting phenomena across languages, particularly cases where downstep or downdrift, both tonal lowering phenomena, occur at prosodic boundaries. ${ }^{7}$

Languages outside of Guébie require antifaithfulness to scalar input values in certain morphosyntactic contexts, and specifically a pitch drop between word boundaries, which makes a constraint like PITCHDROP typologically motivated.

Note that there is nothing built into PITCHDROP, or constraints like NoHIGHER and Higher, which addresses the locality of the Guébie scalar tone shift. The final subject tone raises and the initial verb tone lowers. We could build in the locality of the pitch drop, either as part of the antifaithfulness constraint, as in PITCHDROP', below, or via indexed faithfulness constraints.

\section{PITCHDROP'}

Assign one violation if the output subject tone is not relatively higher than the verb tone on the four-tone scale than it was in the input.

\begin{tabular}{cc} 
Input & Output \\
\hline FST - IVT $=n$ & FST - IVT $=n+1$
\end{tabular}

The PITChDrop' constraint above is an indexed constraint, in that it references particular syntactic positions, terminal nodes, or features. Cophonology Theory in its pure form specifically disallows indexed constraints (Orgun 1996; Inkelas and Zoll 2005, 2007). If we were to adopt the original PITCHDROP constraint in (24); the phonology would need another way to determine the locality of the pitch drop, targeting only the juncture between subject and verb. While I acknowledge that future work might determine that other combinations of constraints better derive the optimal

\footnotetext{
${ }^{7}$ Note that this constraint could also be rephrased in Match Theory terms (Selkirk 2009, 2011), where a prosodic word boundary would correspond with a particular syntactic boundary, and a pitch drop would be motivated at that prosodic boundary.
} 
result, I adopt PITCHDROP' here, which motivates both the locality and antifaithfulness of the imperfective scalar shift. ${ }^{8}$ While the ingredients of this constraintantifaithfulness and indexation to the juncture between subject and verb-have been proposed before, they have not been combined in this way. The complexity of this constraint mirrors the unique character of the Guébie imperfective scalar shift.

In Guébie, the imperfective feature is a morpheme with no input phonological content. However, it is realized via tonal changes to the subject and verb triggered by the PITCHDROP' constraint. I assume that faithfulness constraints such as MAX and DEP are highly ranked here, ruling out segmental changes, and I only consider candidates which realize the imperfective morpheme via tonal changes.

Along with PITCHDROP', we need an input-output faithfulness constraint. This identity constraint must be defined in a scalar manner, where the further along the scale an output element is from the original input, the more violations are incurred (cf. Kirchner 1997). The scalar evaluation of ID-TONE is necessary to ensure that the optimal candidate only minimally differs on the tonal scale from the corresponding input tone (Table 8c).

\section{ID-TONE}

Assign one violation for each step on the tone scale that an output tone differs from its corresponding input tone.

The following tableau shows the ranking of PITCHDROP' and the gradiently evaluated tonal faithfulness constraint in the imperfective grammar. I set aside discussion of the elsewhere grammar for now, knowing that faithfulness must be undominated in the elsewhere (perfective) context. I return to the constraint ranking of the elsewhere grammar in (Sect. 3.2.2).

Because Ds are considered to be syntactic phase heads, and the subject is inside a DP, it will have already been spelled out by the time the CP containing the imperfective morpheme is phonologically evaluated. However, the tone of a subject DP can be manipulated in imperfective contexts, so our model must allow for the phonological content of spelled out phases (like DP) to be manipulable. I follow Michaels (2013), Surkalović (2013) and McPherson and Heath (2016) in saying that phonolog-

Table 8 PITCHDROP' 》 ID-TONE

\begin{tabular}{|l||c|c|}
\hline $\mathrm{e}^{4} \mathrm{li}^{3} \mathrm{ipfv}$ & PITChDroP' & ID-TONE \\
\hline \hline a. $\mathrm{e}^{4} \mathrm{li}^{2}$ & & $*$ \\
\hline b. $\mathrm{e}^{4} \mathrm{li}^{3}$ & $* !$ & \\
\hline c. $\mathrm{e}^{4} \mathrm{li}^{1}$ & & $* * !$ \\
\hline
\end{tabular}

\footnotetext{
${ }^{8}$ An alternative to an indexed antifaithfulness constraint is to use indexed faithfulness constraints such as IDENT-PHASE(DP), which would be ranked relatively low, and IDENT-PHASE(VOICEP), which would be ranked relatively high to rule out a pitch drop between the verb and a following object, which is within the VoiceP phase. See (27) and the discussion preceding it on phase identity constraints.
} 
Table 9 PITCHDROP' $\gg$ ID-PHASE 》ID-TONE

\begin{tabular}{|l||c|c|c|}
\hline $\mathrm{e}^{4} \mathrm{li}^{3}{ }_{\mathrm{ipfv}}$ & PITChDROP & ID-PHASE & ID-TONE \\
\hline \hline a. $\mathrm{e}^{4} \mathrm{li}^{3}$ & $* !$ & & \\
\hline b. $\mathrm{e}^{4} \mathrm{li}^{2}$ & & & $*$ \\
\hline c. $\mathrm{e}^{4} \mathrm{li}^{1}$ & & & $* * !$ \\
\hline d. $\mathrm{e}^{5} \mathrm{li}^{3}$ & & $* !$ & $*$ \\
\hline e. $\mathrm{e}^{4} \mathrm{li}^{4}$ & $* !$ & & $*$ \\
\hline f. $\mathrm{e}^{3} \mathrm{li}^{3}$ & $* !$ & $*$ & $*$ \\
\hline
\end{tabular}

ical content of phases is indeed manipulable after spell-out, but that IDENT-PHASE constraints protect previously phonologically evaluated content.

IDENT-PHASE (adapted from McPherson and Heath 2016, 613)

Assign one violation if the phonological content of a previously spelled-out phase is distinct in the output from the input.

While IDENT-PHASE plays a role in ruling out tonal alternations between other adjacent words in the phase such as verb and object, I only consider intransitive verbs here (subject and verb) for the sake of simplicity.

The constraints in Table 9 rule out a faithful imperfective candidate (candidate 9a), as well as those candidates which realize the imperfective morpheme by lowering the verb tone to too far (candidate 9c), raising the subject (candidate 9d), raising the verb (candidate 9e), or lowering the subject (candidate 9f). This ranking accounts for all cases where the input verb tone is higher than 1 .

To account for subject raising in cases where the verb is already low, we need to say something more in order to get the correct output (Table 10).

The current set of constraints will always choose the candidate where the difference from input to output involves lowering the initial verb tone one step. This incorrectly predicts a super-low tone on the verb in Table 10 . In order to ensure that the candidate with a super-low tone on the verb, (candidate 10b), does not win, I propose a markedness constraint $* 0$ which ensures no super-low tones in the output. This constraint is highly motivated in Guébie because we never see a surface super-low tone. It is also typologically motivated, because super-low tones are quite uncommon

Table 10 PITCHDROP' $\gg$ ID-PHASE $\gg$ ID-TONE for a low-toned verb input

\begin{tabular}{|l||c|c|c|}
\hline $\mathrm{e}^{4} \mathrm{pa}^{1}{ }^{\mathrm{ipfv}}$ & PITChDROP & ID-PhASE & ID-TONE \\
\hline \hline a. $\mathrm{e}^{4} \mathrm{pa}^{1}$ & $* !$ & & \\
\hline b. $\mathrm{e}^{4} \mathrm{pa}^{0}$ & & & $*$ \\
\hline c. $\mathrm{e}^{5} \mathrm{pa}^{1}$ & & $* !$ & $*$ \\
\hline d. $\mathrm{e}^{4} \mathrm{pa}^{2}$ & $* !$ & & $*$ \\
\hline e. $\mathrm{e}^{3} \mathrm{pa}^{1}$ & $* !$ & $*$ & $*$ \\
\hline
\end{tabular}


Table $11 * 0$, PITCHDROP’ $\gg$ ID-PHASE $\gg$ ID-TONE

\begin{tabular}{|c|c|c|c|c|}
\hline $\mathrm{e}^{4} \mathrm{pa}_{i p f v}^{1}$ & $*_{0}$ & PITCHDROP & ID-PHASE & ID-TONE \\
\hline a. $\mathrm{e}^{4} \mathrm{pa}^{1}$ & & $* !$ & & \\
\hline b. $\mathrm{e}^{4} \mathrm{pa}^{0}$ & $* !$ & & & * \\
\hline c. $\mathrm{e}^{4} \mathrm{pa}^{2}$ & & $* !$ & & * \\
\hline d. $\mathrm{e}^{5} \mathrm{pa}^{1}$ & & & * & * \\
\hline e. $\mathrm{e}^{3} \mathrm{pa}^{1}$ & & *! & * & * \\
\hline
\end{tabular}

cross-linguistically. They are less common than, for example, super-high tones (cf. Hyman's database of tonal inventories in 662 languages worldwide, Hyman p.c.). ${ }^{9}$

$* 0$

Assign one violation for every instance of a super-low tone in the output.

The addition of this constraint results in the desired optimal candidate, the subject raising candidate, (d) in Table 11.

Tableaux 9 and 11 show that the proposed constraint ranking accounts for tonal shift in the imperfective grammar. I include comparative markedness tableaux for the final rankings in Table 12, to show how the proposed constraints interact to result in the correct optimal candidates (Prince 2000; McCarthy 2003).

In the comparative markedness tableau, we can see that the *0 and PiTcHDroP' constraints favor the winner in both verb lowering and subject raising contexts. IDPHASE must be ranked lower because in subject raising contexts, this constraint favors losing candidates, namely those that do not involve a tone change to the subject DP. ID-TONE must be ranked lowest of all because it favors a losing candidate, namely the faithful one, in both subject raising and verb lowering contexts. These four constraints, ranked as above in the imperfective cophonology, account for both initial verb tone lowering and final subject tone raising in imperfective contexts.

Table 12 A comparative markedness representation

\begin{tabular}{|c|c|c|c|c|}
\hline & $* 0$ & PITCHDROP' & ID-PhASE & ID-TONE \\
\hline$/ \mathrm{e}^{4} \mathrm{li}_{i p f v}^{3} /$ & & & & \\
\hline a. $e^{4} \mathrm{li}^{3}$ & & W & & \\
\hline b. $\mathrm{e}^{4} \mathrm{li}^{2}$ & & & & $\mathrm{~L}$ \\
\hline c. $\mathrm{e}^{4} \mathrm{li}^{1}$ & & & & $\mathrm{~L}$ \\
\hline d. $\mathrm{e}^{5} \mathrm{li}^{3}$ & & & W & $\mathrm{L}$ \\
\hline e. $\mathrm{e}^{4} \mathrm{li}^{4}$ & & $\mathrm{~W}$ & & $\mathrm{~L}$ \\
\hline f. $e^{3} \operatorname{li}^{3}$ & & W & W & $\mathrm{L}$ \\
\hline$/ \mathrm{e}^{4} \mathrm{pa}_{i p f v}^{1} /$ & & & & \\
\hline a. $\mathrm{e}^{4} \mathrm{pa}^{1}$ & & W & & \\
\hline b. $\mathrm{e}^{4} \mathrm{pa}^{0}$ & $\mathrm{~W}$ & & & $\mathrm{~L}$ \\
\hline c. $\mathrm{e}^{4} \mathrm{pa}^{2}$ & & W & & $\mathrm{L}$ \\
\hline d. $\mathrm{e}^{5} \mathrm{pa}^{1}$ & & & $\mathrm{~L}$ & $\mathrm{~L}$ \\
\hline e. $\mathrm{e}^{3} \mathrm{pa}^{1}$ & & W & $\mathrm{L}$ & $\mathrm{L}$ \\
\hline
\end{tabular}

\footnotetext{
${ }^{9}$ While it is more common for tone systems to be described as showing a super-high tone than a super-low tone, this is often a matter of analysis. For examples, what is described as a super-high tone could instead be analyzed as tonal upstep, and a super-low tone as downstep.
} 


\subsubsection{The elsewhere grammar}

The elsewhere grammar, similar to Anttila's (2002) categorical ranking within a language, termed master ranking by Inkelas and Zoll (2005, 2007), is a ranking used when no alternative is triggered by a morpheme within the spell-out domain. In Guébie, the elsewhere grammar evaluates perfective constructions. In such contexts, the only crucial ranking is that faithfulness (ID-PHASE, ID-TONE) must outrank antifaithfulness (PITCHDROP'). This will result in the faithful candidate surfacing every time, as is true of perfective clauses in Guébie.

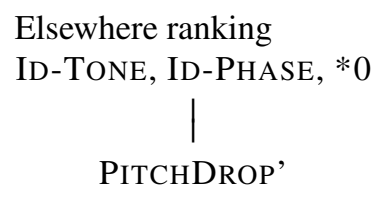

There is no evidence as to the ranking of $* 0$ in the elsewhere grammar. Future nonceword experiments could explore whether it is undominated as in the imperfective grammar, or whether faithfulness outranks $* 0$ in elsewhere contexts.

The drawback of this analysis is that it requires constraint types otherwise not needed in Cophonology Theory, namely, those that reference morphosyntactic categories. However, the proposed analysis has the following benefits: it results in the correct optimal candidates, it uses constraints needed to account for scales and tonal overlays cross-linguistically (cf. scale-referring constraints, anti-identity, and phase identity in De Lacy 2002; Mortensen 2006; McPherson and Heath 2016), and it captures the generalization that only in imperfective contexts, the verb tone lowers if possible; if not, the subject tone raises. Additionally, the cross-word effects are captured by phase-based spell-out, and the non-uniformity of the realization of the imperfective morpheme is captured by the lack of underlying form.

\subsection{Considering alternative analyses}

In this section I consider alternative analyses to the one presented in Sect. 3.2. I begin with an alternative constraint-based approach involving optimal paradigms. I then turn to item-based approaches to scalar tone shift, where I consider whether the imperfective could have an abstract underlying representation which triggers the shift. The final alternative considered is suppletive allomorphy.

\subsubsection{An optimal paradigms account}

One might ask whether other constraint-based models could also account for the Guébie scalar tone data. Specifically, an account that requires contrast within cells of an inflectional paradigm could nicely capture the difference between perfective and imperfective forms.

A paradigm account easily motivates contrast across cells of a verbal paradigm. In Sect. 2.1 we made the generalization that the difference between subject and verb tone in the imperfective is one step greater than in the perfective. This difference between imperfective and perfective could be formulated as a transderivational or paradigmatic constraint, as below. 
*MERGE (Padgett 2003): Assign one violation for each identical pair of cells in a paradigm. ${ }^{10}$

In Guébie, though, only one cell of the verbal paradigm shows a unique form: the imperfective. All non-imperfective contexts (perfective, imperative, future, irrealis, negative, etc.) are identical.

That is, there are only two tonal forms of a given verb, one that surfaces in imperfective contexts, and one that surfaces elsewhere (Table 13).

Table 13 Verbal paradigm for 'eat'

\begin{tabular}{ll}
\hline Context & Surface form \\
\hline Imperative & $\mathrm{li}^{3}$ \\
Uninflected & $\mathrm{li}^{3}$ \\
Perfective & $\mathrm{li}^{3}$ \\
Imperfective & $\mathbf{l i}^{2}$ \\
\hline
\end{tabular}

While an optimal paradigms approach could handle these data by evaluating 2-cell paradigms of 'imperfective' and 'elsewhere', there is no obvious empirical difference between a paradigm-based analysis with 'imperfective' and 'elsewhere' paradigms, and the imperfective and elsewhere cophonologies presented in this paper. Both involve imperfective-specific phonologies.

Additionally, if the imperfective alternation in Guébie affected the surface form of verbs alone, perhaps we could consider a paradigm-based account where imperfective and perfective (elsewhere) forms of a given verb must contrast. However, it is not only verbs that are affected by the imperfective scalar tone shift. Subjects undergo tonal changes as well. This means that every combination of subject and verb would have to maintain contrast across an imperfective/perfective paradigm (I ate, I eat; You ate, You eat; The black dog ate, The black dog eats; etc.), and it is unclear what status this potentially infinite number of paradigms (in the sense that the lexicon is potentially infinite) would have in the grammar of the language.

While an Optimal Paradigms analysis "using constraints like Padgett's (2003) *MERGE" could adequately account for the Guébie facts, it would still need to reference the imperfective form specifically, since imperfective is the only cell in the verbal paradigm with a unique form. In this way, an Optimal Paradigms framework accounts for the same set of facts as the imperfective versus elsewhere cophonologies proposed in Sect. 3.2, and both models specifically pick out the imperfective context as phonologically distinct from the elsewhere case.

\subsubsection{Underlying representations}

In the proposed analysis, a morphosyntactic feature triggers scalar tone shift via constraint interaction. No abstract underlying phonological representation of the imperfective feature is necessary. We could instead consider an analysis where the imperfective morpheme has an abstract underlying form, which itself triggers scalar shift.

\footnotetext{
${ }^{10}$ The definition of *MERGE used here has been adapted from Padgett's original one, "No word of the output has multiple correspondents in the input."
} 
If this underlying representation obfuscates the need for referring to distinct morphological constructions in the phonology (cophonologies), it could be considered simpler than the proposed account. This representational account would favor itembased approaches to morphologically conditioned phonology, as discussed in Sect. 1. However, an abstract underlying representation requires additional lexical material, so if an account using abstract representations must still refer to the imperfective context in addition to a particular lexical form, it would be overall less economical than the analysis proposed in Sect. 3.2.

This section shows that a number of standardly adopted tonal representations (floating tones, features) cannot straightforwardly account for scalar shift; the phonological item itself is not enough to trigger scalar tone shift at the juncture between subject and verb, and reference to morphosyntactic features (imperfective) is necessary, just as in the cophonologies account with no underlying representation. However, if one adopts a significantly complex system of tonal representations plus constraintbased evaluation, a representational account of Guébie scalar tone shift is possible, Sect. 3.3.5. In the latter case, we can avoid multiple cophonologies, which by certain metrics may be simpler than a cophonological account without an underlying phonological representation for the imperfective morpheme, at the cost of a more intricate set of tonal representations.

Recall from Sect. 1 that much current work analyzes all morphology as itembased, or affixal (Benua 1997; Alderete 2001; Wolf 2007; Bermúdez-Otero 2012; Gouskova and Linzen 2015; Zimmermann 2013; Trommer and Zimmermann 2014). On such approaches, even process morphology with no segmental exponent, such as tone shift, tone replacement, vowel alternations, and truncation, is analyzed as itembased.

Here I consider two standard item-based approaches to tone: 1) floating tones and 2) floating tone features. I show that both a floating tone and floating feature analysis require construction-specific rules/constraints, thus they do not fare better than the item-less analysis in Sect. 3.2. I then show that by significantly extending the system of tonal representations, a representational account without cophonologies is possible. The overarching challenge for all approaches is to capture the formula in (5), maintaining contrast between the perfective and imperfective forms of a given verb by manipulating the tone on subject and verb in a scalar manner.

\subsubsection{Floating tones}

One possible representational approach involves a floating tone as the underlying form of the imperfective morpheme in Guébie. This analysis is somewhat appealing, since we already assume discrete tonal units in the underlying forms of Guébie lexical items, as per Sect. 3.1. Let us consider a floating 41 tone as a possible underlying form, or Vocabulary item in Distributed Morphology terms, for the imperfective morpheme. This is a reasonable candidate because, if situated between the subject and verb as in (31), the low second portion of the 41 tone could trigger lowering of the verb, while the high initial portion could trigger raising of the subject. 
Floating tone underlying representation

Subj Aspect Verb

$\mathrm{e}^{4} \quad 41 \quad \mathrm{li}^{3}$

1SG.NOM IPFV eat

'I eat.'

Any account of the Guébie scalar shift must explain the following four generalizations: 1) why we get verb tone lowering in the default imperfective case (i.e. the output of (31) should result in verb tone lowering from 3 to 2 in the imperfective), 2) why the verb doesn't lower to super-low when it starts low, 3) under what conditions the subject raises, and 4) why a 41 melody has a scalar effect in imperfective contexts, but not elsewhere. Verb lowering as the default operation and subject raising only if the verb is already low could be incorporated into the analysis via constraints. Like the process-based account presented in Sect. 3.2, these constraints would still need to reference the imperfective context, because tones 4,1 , and 41 do not have a scalar effect in other environments. Verb-lowering and subject-raising constraints are needed in both process- and item-based accounts, and in the process-based analysis with no UR we avoid an arbitrary underlying form.

A floating tone analysis would need to explain why that particular (i.e. falling 41) tone has a scalar effect in imperfective contexts, but not elsewhere. There are twelve possible two-tone contours given the four tone heights in Guébie (Table 1). Seven of these twelve contours and the four level tone melodies (heights 1-4) are found on Guébie roots and affixes, and the other melodies appear in derived contexts. There is no instance of any of these contour or level melodies triggering raising or lowering of nearby tones. This weakens the argument that the imperfective morpheme is a floating tone, since there is no reason to believe that the presence of a given tone should trigger a raising or lowering process in this one context (imperfective), but nowhere else in the language. The analysis would need to make use of a cophonology or indexed constraint specific to imperfective contexts in order to get the desired result of scalar shift in the imperfective, but not elsewhere. Doing so results in two levels of complexity: 1) an underlying form, and 2) morpheme-specific constraints. The analysis proposed in Sect. 3.2 requires only one such level of complexity.

In addition to the challenges above, another difficulty for a floating tone analysis is determining whether the chosen floating tone is the right one. For example, we said that the underlying form of the imperfective could be a 41 tone. However, we could have chosen any other underlying form, perhaps 14 , and the constraints needed to get the facts to fall out would be exactly the same as for the 41 analysis. In both cases, we need to motivate verb lowering and subject raising via constraints or rules in imperfective contexts only. That is, choice of underlying form makes no predictions about the surface alternations; imperfective-specific constraints do the work. No matter which UR we choose, our constraints must refer both to the underlying form, and to the imperfective context (ex: in imperfective contexts, 41 lowers the tone of the following verb one step).

In summary, we cannot avoid referencing the imperfective context in modeling the Guébie scalar shift; however, we can avoid adding an imperfective underlying form to our model. 


\subsubsection{Binary floating tone features}

Instead of modeling the imperfective morpheme as a floating tone, we could instead model it as a floating feature. A number of tonal features for four-tone-height languages have been proposed (Table 14).

Table 14 Proposed features for 4-tone systems

\begin{tabular}{|c|c|c|c|c|c|c|c|c|c|}
\hline \multirow[t]{2}{*}{ a. $Y$} & \multicolumn{5}{|c|}{ Yip (1980), Pulleyblank (1986) } & 4 & 3 & 2 & 1 \\
\hline & Upper & & & & & + & + & - & - \\
\hline & High/Raised & & & & & + & - & + & - \\
\hline \multirow[t]{3}{*}{ b. } & Clements (19 & 83), & nide & (1999 & & 4 & 3 & 2 & 1 \\
\hline & Feature 1 & & & & & $\mathrm{H}$ & $\mathrm{H}$ & L & $\mathrm{L}$ \\
\hline & Feature 2 & & & & & $\mathrm{H}$ & L & $\mathrm{H}$ & L \\
\hline c. & Ваo (1999) & 4 & 3 & 2 & 1 & & & & \\
\hline & Stiff & + & + & - & - & & & & \\
\hline & Slack & - & + & - & + & & & & \\
\hline
\end{tabular}

In all proposed sets of binary features presented above, there is a single-feature difference between high (tone 4) and mid-high (tone 3) tones, and a single-feature difference between mid (tone 2) and low (tone 1) tones, but there are two feature values differentiating mid-high (tone 3 ) from mid (tone 2) tones. This means that the natural classes predicted by the above feature sets are $\{4,3\},\{4,2\},\{3,1\}$, $\{2,1\}$, but crucially not $\{3,2\}$. This feature set works nicely for those languages where the highest tone (tone 4) and mid-low tone (tone 2) pattern together, while the mid-high tone (tone 3 ) and low tone (tone 1) pattern together, or where the two high tones and two low tones share properties. Such relationships are found in a number of languages, including Gban, a Mande language spoken on the border of Kru languages in Côte d'Ivoire, near where Guébie is spoken (Zheltov 2005, 25), and further examples discussed by Clements et al. (2011) and Hyman (2010). However, for any four-tone language where we see an alternation between tones 2 and 3, like Guébie, binary features become problematic.

While the tone shifts from tone 4 to 3 and from 2 to 1 in Guébie involve a single featural change, that same featural change cannot on its own be responsible for the shift from 3 to 2, because tones 3 and 2 differ in two features in all of the above sets. The failure of binary features to account for scalar phenomena has been understood since at least Contreras (1969).

If we assume that Guébie scalar lowering in imperfective contexts is a unitary phenomenon, a binary floating feature account does not work. ${ }^{11}$

\footnotetext{
${ }^{11}$ See McPherson (2016) for a recent binary feature account of a scalar tone shift in Seenku. A featural account works for Seenku because there are only two underlying tones which undergo shift: extra-low becomes low, and high becomes extra-high in plural contexts. A featural analysis becomes obsolete in a system with more than two underlying tones, like the four-tone system of Guébie.
} 


\subsubsection{Cumulative relational tone features}

Rather than adopting a binary feature model, this section considers a cumulative tonal feature set, where the minimal units are $[\mathrm{h}, \mathrm{l}]$ and multiple minimal units can be linked to a single tonal root node. ${ }^{12}$ Each tonal root node is equivalent to a single level tone. Tonal root nodes are linked to tone bearing units (syllables, in Guébie); if multiple root nodes are linked to the same tone bearing unit, a contour tone will surface. This approach resembles the cumulative features used to account for vowel height by Parkinson (1996), as well as the dynamic tonal features of Clark (1978), but with key differences in order to extend their models to a four-tone system where we see both lowering and raising of underlying tones.

In this approach, each surface level tone $(1,2,3,4)$ would have the underlying representation in (32). The superscripts on the tone-bearing units in (32) are not a meaningful part of the representation, but are present to clarify which representation corresponds to which surface tone.

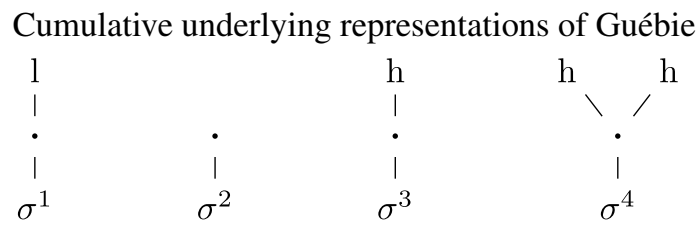

In this representational approach, surface tone 2 could be written with an $[\mathrm{h}]$ and an [1] both connected to the same root node, but in order for the rest of the facts to work out, we must assume that an [h] and an [1] cancel each other out in this framework.

A contour tone would be represented as in (33), with two tonal root nodes each associated with a single tone-bearing unit.

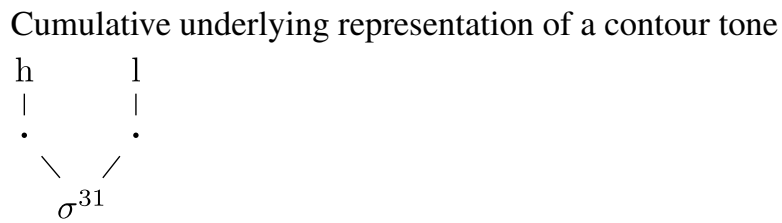

Tone raising could be accounted for by adding a single [h] unit to each of the level tone representations in (32). Adding an [h] to the representation for a low-toned syllable, $\sigma^{1}$, results in a [h] and [1] both connected to the same root node. As mentioned above, an [h] and [1] cancel each other out, which results in no minimal tonal unit on the surface, the representation of $\sigma^{2}$. Adding an [h] to the representation for $\sigma^{2}$ results in a single [h], which is the representation for a surface $\sigma^{3}$, a mid-high tone. Adding an [h] to the single [h] of $\sigma^{3}$ results in a surface $[\mathrm{h}, \mathrm{h}]$, which is the representation of $\sigma^{4}$. In this approach we can also add an [h] to the [h, h] of $\sigma^{4}$ to get $[\mathrm{h}, \mathrm{h}$, h], resulting a surface super-high tone, $\sigma^{5}$.

\footnotetext{
${ }^{12}$ Thanks to an anonymous reviewer for pointing out this possible representational account.
} 
To result in lowering one step, we could instead add a [1] to the level tone representations. Adding a [1] to [h, h] would result in one set of [h] and [1] canceling each other out, leaving behind a single [h], surface $\sigma^{3}$. Adding [1] to a single [h] results in no minimal tonal unit, since the two cancel each other out, surface $\sigma^{2}$. Adding [1] to a null tonal representation results in a single [1], the representation of a low tone, $\sigma^{1}$. A separate rule or constraint must rule out a $[1,1]$ super-low tonal node in this framework, to avoid a low tone becoming super low with the addition of another [1].

Given the above lowering and raising transformations, which result from addition of a [h] or [1] minimal tonal unit, we could posit the underlying form in (34) for the imperfective morpheme.

\section{Imperfective underlying form}

h 1

In the representation above, there are floating minimal tone units $[\mathrm{h}, \mathrm{l}]$, which are not associated to a root node. Via constraints specifying that each morpheme must be realized (REALIZEMORPH), the above morpheme either surfaces by associating a [1] to the following tonal root node, resulting in lowering of the first verbal level tone, or by associating an $[\mathrm{h}]$ to the preceding tonal root node, resulting in raising of the final subject level tone. ${ }^{13}$

Much like the cophonologies account in Sect. 3.2, we must still specify via constraints that the imperfective tonal phenomenon sometimes affects the following verb, and other times affects the preceding subject. We must also specify via constraints that the default realization of the imperfective is to surface on the following verb, and that surfacing on the preceding subject word is a last resort, only applying if the verb is underlyingly low. Just as in the cophonologies account, this requires constraints that make reference to morphosyntactic features or categories.

First, a constraint would need to specify that the floating [h, l] can only surface by associating the [h] the preceding root node and the [1] to the following root node; it is not possible for the [h] to associate to the following root node as in (35). In (35), we begin with a subject and verb of tone height 3 (with a single root node associated to a single $[\mathrm{h}]$ ). Then the floating $[\mathrm{h}]$ of the imperfective associates to the following root node, the verb.

\footnotetext{
${ }^{13}$ The proposed representations are similar to Parkinson's (1996) proposed monodirectional scalar features for vowel height. However, Parkinson uses a single cumulative minimal unit [closed], rather than two separate minimal units as in the proposed tonal account. The more [closed] features present, the higher the vowel. Because there is only one type of minimal vowel height unit in his model, which increases height, any floating vowel-height feature will have a [closed] feature, and will only be able to increase, not decrease, vowel height of a surrounding morpheme, by adding a [closed feature]. He sees the fact that vowel lowering is not predicted by his model as a benefit, since we don't see scalar vowel lowering processes across languages. However, for a representational model of tone, we need features that will trigger both lowering and raising processes to apply. Thus, we need two minimal units in the account of Guébie scalar tone shift presented here.
} 
Impossible association in Guébie

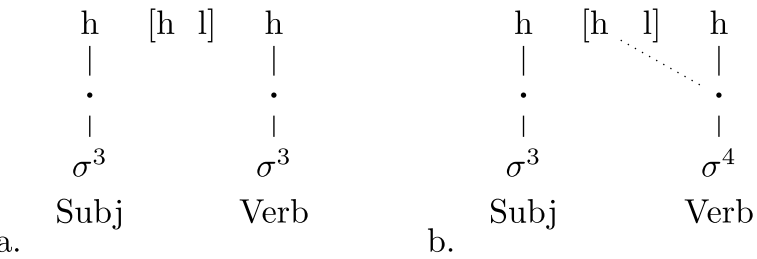

A constraint against skipping minimal tone units when associating them to root nodes could rule out a structure derived as above, where (35a) is the underlying form, and in (35b), the surface form, the left-most imperfective tonal unit [h] associates to the verb on the right. Constraints referencing minimal tonal units and root nodes are necessary to manipulate the extended underlying representations in this model.

*SKIPPINGASSOCIATION: Assign one violation for each root node that is associated to non-consecutive minimal tonal units.

The structure in $(35 b)$ would incur a violation of *SKIPPINGASSOCIATION because the second tonal root node is associated to two non-consecutive minimal tonal units. This constraint prohibits verbs from associating to the [h] unit of the imperfective, resulting in raising, and would also prohibit subjects from associating with the [1] unit of the imperfective, resulting in lowering.

In order for [1] association to the following verbal root node to be the default realization of the [h l] imperfective morpheme, we have two options: 1) we can specify that verbs are more susceptible to input-output change than are noun phrases, or 2) we can specify that in general, tone lowering is preferred to tone raising. The former requires constraints to be indexed to morphosyntactic categories, a theoretical tool not otherwise necessary on this account, so I adopt the latter.

NoHigher (adapted from Mortensen 2006): Assign a violation for any tone bearing unit which surfaces with tone higher on the four-tone scale than the corresponding input tone bearing unit.

This constraint must be outranked by *SKIPPINGASSOCIATION and *0 (prohibiting [1 1] on a single root node), but must crucially outrank HIGHER.

$$
\begin{aligned}
& \text { HIGHER (adapted from Mortensen 2006): Assign a violation for any tone } \\
& \text { bearing unit which does not surface with output tone higher on the four-tone } \\
& \text { scale than the corresponding input tone bearing unit. }
\end{aligned}
$$

Note that HigHER is an antifaithfulness constraint, much like the formulation of the PITCHDROP constraint in Sect. 3.2.

The above constraints, ranked together with a scalarly evaluated tonal faithfulness constraint, such as IDENTTONE proposed in Sect. 3.2, result in the correct output in both verb lowering and subject raising cases. The ultimate ranking is given in (39).

$$
\begin{aligned}
& \text { Cumulative representation ranking } \\
& \text { REALIZEMORPH, *SKIPPINGASSOCIATION, *0 } \gg \text { NOHIGHER } \gg \\
& \text { HIGHER } \gg \text { IDENTTONE }
\end{aligned}
$$

As I see it, there are both pros and cons to this approach. 
The first benefit of this representational approach is that we need not specify an imperfective-specific phonological grammar. Scalar tone shift only applies in imperfective contexts because that is the only place where we posit an underlying floating tonal minimal unit. The presence of the underlying tonal imperfective morpheme results in scalar shift, and the lack of underlying tonal representation in other tense/aspect combinations results in no change from the input to output verbal form. The second is that the locality of the pitch drop only surfacing on the final tone of the subject or initial tone of the verb is straightforwardly accounted for by the locality of the underlying $[\mathrm{h}, \mathrm{l}]$ imperfective morpheme.

These two benefits of the cumulative representational approach come at the cost of expanding the machinery needed to represent tonal contrasts in the grammar, of positing constraints that reference tonal root nodes in addition to minimal tonal units and tone-bearing units, and of positing any underlying phonological form at all for the imperfective morpheme. Thus, we are trading one level of simplicity in the grammar (lack of complex tonal representations and constraints that refer to those representations) for another (a single constraint ranking for the language, rather than multiple), as summarized in Table 15.

Table 15 Comparing complexities of analyses

\begin{tabular}{lll}
\hline & Cumulative URs & Cophonologies \\
\hline Indexed constraints? & No & Yes \\
Multiple grammars? & No & Yes \\
Root nodes needed? & Yes & No \\
UR for imperfective? & Yes & No \\
Antifaithfulness constraints? & Yes & Yes \\
\hline
\end{tabular}

While both analyses are complex in different ways, it is difficult to determine which of multiple phonological grammars or abstract underlying representations is more complex. In terms of acquisition, the representational account would require a speaker to learn a system of tonal representations only necessary to account for a single morpheme in the language. The cophonologies account would require learning a constraint ranking that applies only in one morphosyntactic context. I opt in favor of cophonologies over abstract representations here; see O'Hara $(2017,326)$ on why computational learners perform better with "minimally abstract" underlying representations, where abstractness is determined by how many features or components of the underlying form appear in its surface exponents.

\subsubsection{Interim summary: Underlying representations lack insight for scalar shift}

In the Guébie scalar tone shift pattern there is no assimilation to or dissimilation from a target. Instead, this is a relational shift in tone, where the difference between subject and verb tone changes between the perfective or underlying form and the imperfective output. For this reason, there is no best underlying representation for the imperfective morpheme in Guébie. There is no single feature change or floating tone that would result in lowering one step in some contexts and raising one step in others without also referencing morphosyntactic context. The best analysis involving 
underlying representations seems to be the cumulative tone representation system in Sect. 3.3.5, which requires three underlying tonal tiers (minimal tonal units, tonal root nodes, and tone-bearing units) plus constraints to determine the optimal output. I propose that instead, the imperfective morpheme has no underlying phonological form in Guébie, but construction-specific constraint rankings that require a difference between input and output best capture the scalar tone shift pattern (Sect. 3.2).

Returning to the discussion of morphologically conditioned phonology versus process morphology in Sect. 1, I conclude based on the Guébie scalar tone shift data that a complete theory of morphology must allow for non-affixal as well as affixal morphology. Morphosyntactic-specific phonological processes occur alongside, and independent of, affixal morphology. For Guébie, I claim that the imperfective morpheme lacks an underlying phonological representation, and instead triggers a phonological process, as discussed in Sects. 3.1 and 3.2. I now turn to another set of alternative analyses in Sect. 3.3.7, where I demonstrate that the suppletive allomorphy is not a reasonable analysis of productive phonological processes like Guébie scalar tone shift.

\subsubsection{Suppletive allomorphy}

Here I consider and argue against two suppletive approaches to Guébie scalar tone shift: Distributed Morphology suppletive allomorphy (Halle and Marantz 1993, 1994; Embick and Noyer 2007; Embick and Halle 2005; Harley 2014; Siddiqi 2009; Haugen and Siddiqi 2013) and Emergent Morphology (Archangeli and Pulleyblank 2012, 2015, 2016).

Suppletive allomorphy involves separately listed lexical items or Vocabulary items. In DM, these allomorphs are each inserted into a derivation in distinct morphosyntactic environments before the phonological grammar applies. ${ }^{14}$ In Archangeli and Pulleyblank's (2016) Emergent Morphology, all surface allomorphs are listed as possible output candidates, and the optimal one is chosen during constraint evaluation. Both of these suppletive approaches are found to be insufficient for the same reason; namely, the list of possible allomorphs needed to account for Guébie scalar tone shift is infinite, thus cannot be lexically listed.

In the early days of DM, suppletive allomorphy was only possible for functional morphemes. Now, though, most DM practitioners agree that both lexical and functional elements can have listed allomorphs, and that the conditioning environment must be sufficiently syntactically local in order to trigger one allomorph or another (Siddiqi 2009; Harley 2014; Toosarvandani 2016). For the verb 'eat' in Guébie, used frequently in examples throughout this paper, there would be two lexically listed allomorphs on a DM suppletive allomorphy account (40).

\footnotetext{
${ }^{14}$ Another strategy for modeling allomorphy in Distributed Morphology is to use Readjustment Rules (Halle and Marantz 1993, 1994; Embick and Noyer 2001), transformational rules that apply to single lexical items or subsets of lexical items in certain morphosyntactic contexts. Readjustment Rules have been argued against for two main reasons: 1) There is no theory of the form a readjustment rule can take; they are unconstrained (Siddiqi 2009; Bye and Svenonius 2012; Gribanova 2015). 2) They involve transformational rules, which are otherwise absent from DM and the Minimalist Program in general (Siddiqi 2009, 42). Setting aside these issues, readjustment rules are a means of dealing with exceptional phonological alternations. Since the imperfective pattern examined here is not exceptional, but applies to every imperfective subject and verb, I do not consider Readjustment Rules further here.
} 
Vocabulary entries for the Guébie verb $l i$, 'to eat'

$-\mathrm{li}^{2} \longleftrightarrow[\mathrm{IPFV}]: \sqrt{e a t}$

$-\mathrm{li}^{3} \longleftrightarrow \sqrt{e a t}$

The representation would be similar in Emergent Morphology, but instead of an insertion rule, constraints determine which allomorph surfaces in each context.

In DM, the tone 2 allomorph of 'eat' would be inserted in the environment of an imperfective feature, and the tone 3 allomorph would be inserted everywhere else. However, suppletive allomorphy does not imply that any regular phonological relationship holds between one form of a Vocabulary item (VI) and another. Thus, on such an account it would be coincidental that every verb whose 'elsewhere' form does not have tone 1 would have two segmentally identical Vocabulary entries, one inserted in imperfective contexts, whose initial tone level is exactly one step lower than in the allomorph underspecified for insertion environment.

A suppletive analysis of verbal tone allomorphy would also require that verbs with tone melodies that we otherwise never see underlyingly be listed in the lexicon. For example, when a verb with tone melody 31 , such as /pa 31 , 'flip', in (10a), surfaces in imperfective contexts, the first tone is lowered from 3 to 2 , resulting in a 21 melody on the surface (10b). The melody 21 is not attested lexically, and only appears in derived contexts. However, under a suppletive analysis, verbs with non-imperfective 31 melodies would have two lexically listed allomorphs, one with tone 31 , and another with tone 21 . The suppletive analysis loses the generalization that 21 only appears in derived contexts, which falls out naturally from an analysis deriving the 21 melody in imperfective contexts via lowering.

While the suppletive allomorphy account is already uneconomical when considering verbal Vocabulary entries, we must also consider that every possible word that can end a subject noun phrase must also have two entries, one whose final tone is exactly one step higher than the other. This is necessary to model the surface result of subject tone raising in contexts where the verb tone is low as suppletion. The problem here is that the set of words that could end a subject noun phrase is potentially infinite. The same problem of an infinite lexicon holds for Emergent Morphology. All non-low verbs and all possible subjects would need to be listed, and would have two phonologically predictable listed forms.

The limitation of a suppletive allomorphy approach to Guébie scalar tone shift is clear; it results in a grossly uneconomical lexicon. Additionally, it fails to capture the generalization that the relationship between imperfective verbs and other forms of the same verb is phonologically predictable.

\section{Other instances of tonal morphology in Guébie}

The scalar tone shift presented in Sect. 2.1 is situated within a larger system of tonal morphophonology in Guébie. In addition to the imperfective scalar tone shift, there are other instances of tonal morphology involving scalar shifts and tone replacement (also called tonal overlays). In this section I discuss two such tonal phenomena. The first is another instance of scalar tone shift, and the second is a tonal overlay process which I show can be handled by the same structure as used to analyze the scalar 
data. What the tonal processes in Guébie have in common is that they all involve a systematic tone change in the environment of a particular morphosyntactic feature.

\subsection{Case marking via scalar tone shift}

Just like the scalar tone shift in imperfective contexts, there seems to be a scalar tonal relationship between nominative and accusative pronouns in Guébie. Object pronouns in Guébie, which surface immediately after the auxiliary or inflected verb, display lexical tone (Table 16) while those in subject position surface one step higher (Table 17).

Table 16 Object pronouns in Guébie

\begin{tabular}{|c|c|c|c|c|c|}
\hline & \multicolumn{2}{|l|}{ Human } & & \multicolumn{2}{|c|}{ Non-human } \\
\hline & Singular & Plural & & Singular & Plural \\
\hline 1 st & $\mathrm{e}^{3}$ & $a^{1}$ & $1 \mathrm{st}$ & - & - \\
\hline 2nd & $\mathrm{e}^{1}$ & $\mathrm{a}^{2}$ & 2nd & - & - \\
\hline $3 \mathrm{rd}$ & $\partial^{2}$ & $\mathrm{wa}^{2}$ & $3 r d$ & $\varepsilon^{2}, \mathrm{a}^{2}, \mho^{2}$ & $\mathrm{i}^{2}, \mathrm{wa}^{2}$ \\
\hline
\end{tabular}

Table 17 Subject pronouns in Guébie

\begin{tabular}{lllllll}
\hline & Human & & & \multicolumn{2}{l}{ Non-human } \\
\cline { 6 - 7 } & Singular & Plural & & Singular & Plural \\
\hline 1st & $\mathrm{e}^{4}$ & $\mathrm{a}^{2}$ & 1 st & - & - \\
2nd & $\mathrm{e}^{2}$ & $\mathrm{a}^{3}$ & 2 nd & - & - \\
3 rd & $\mathrm{o}^{3}$ & $\mathrm{wa}^{3}$ & $3 \mathrm{rd}$ & $\varepsilon^{3}, \mathrm{a}^{3}, \mathrm{v}^{3}$ & $\mathrm{i}^{3}, \mathrm{wa}^{3}$ \\
\hline
\end{tabular}

When they appear in subject position, pronouns surface immediately before the auxiliary or inflected verb, and systematically surface with tone one step higher than their object counterparts.

I assume that the featural difference between subject and object pronouns is nominative versus accusative case. Tone raising on nominative pronouns is not a general process affecting all subjects, because only pronouns show a difference in tone when in object versus subject position (independent of the imperfective scalar tone shift discussed in Sect. 2.1). Full noun phrases do not show a tonal difference between subject and object position (41).

(41) Full noun phrases do not show a case distinction
a. $\mathrm{ju}^{4} \quad \mathrm{ni}^{3} \quad=\mathrm{o}^{2} \quad \mathrm{ji}^{3}$
child see.IPFV $=3$ SG. ACC PART
'The child sees him.'
b. $\mathbf{o}^{3} \quad \mathrm{ni}^{3} \quad \mathrm{ju}^{4} \quad \mathrm{ji}^{3}$
3SG.NOM see.IPFV child PART
'He sees the child.'

The noun 'child' in (41) has the same tone in subject position (a) and object position (b). Just like in English, then, only pronouns show overt case distinctions. We could explain this by saying that pronouns contain a different amount of syntactic structure 
than other noun phrases in Guébie, or that the nominative case assigner in Guébie probes for a feature that only pronouns have, and that other nouns do not require case licensing (cf. Preminger 2011).

The analysis presented in Sect. 3 easily extends to the nominative scalar tone shift. In the environment of a morphosyntactic nominative case feature, the nominative cophonology applies. In this cophonology, which applies at the level of a DP phase, a tonal antifaithfulness constraint, perhaps HIGHER, outranks faithfulness constraints like ID-TONE. ${ }^{15}$ The optimal candidate is then the one where the tone of the nominative pronoun is one step higher than the input tone. The fact that this same set of constraints is needed in multiple cophonologies supports the choice of such constraints in the Guébie grammar.

In a nominative DP and an imperfective $\mathrm{CP}$, a single pronoun can then undergo two tonal shifts. For example, the third person singular human pronoun in (41b) has the underlying form $/ \mathrm{s}^{2} /$. Because it surfaces in a nominative DP, it raises one step to $\left[0^{3}\right]$ during phonological evaluation of the DP phase. When that nominative DP surfaces inside of a CP containing an imperfective feature, and the following verb has an underlying low tone, the pronoun will raise again to $\left[\mathrm{o}^{4}\right]$ during evaluation of the CP phase, as in (42).

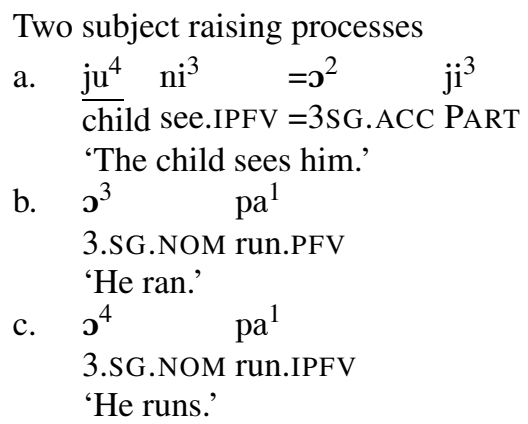

There is very little language-internal evidence for choosing either the nominative or accusative pronoun series as the lexical form. This is because pronouns in ellipsis contexts such as 'Me, no!', as the object of a postposition, and in focus constructions such as 'Him, I like' use an emphatic pronoun series, rather than the nominative or accusative form of a pronoun. There is, however, a typological argument supporting the claim that accusative pronouns surface with the same tone as the underlying form, while the tone on nominative pronouns is derived. For languages that show case distinctions in Africa, it is normally nominative case which is marked (Creissels et al. 2008:87-91); see also König 2006 on marked nominative systems in East Africa. If the accusative pronoun shows lexical tone, Guébie represents another case

\footnotetext{
${ }^{15}$ For space reasons I do not detail the syntax of pronouns versus other noun phrases here, but any model of nominative case in Guébie must account for the fact that only pronouns are affected by this nominative tone raising. If syntactic properties of pronouns indeed convince us that pronouns contain more syntactic structure than other noun phrases, this constraint might actually target something larger than a DP, say a KP (case phrase). Alternatively, we could say that nouns need not be licensed by case in Guébie (see Jenks and Sande's (to appear) analysis of case in Moro), and only pronouns are ever assigned case to begin with, so the nominative cophonology will only ever apply when a pronoun is in subject position.
} 
of a marked nominative language in Africa, conforming to the areal features of the Macro-Sudan Belt.

Unlike the tone on verbs, we cannot base our analysis of which form is lexical on the quality of the tones themselves (there is no super-high tone on pronouns, for example). Because the inventory of pronouns is limited to those in Tables 16 and 17, we cannot further probe the pronoun system for evidence that accusative is the underived case. Either way, the model presented in Sect. 3.1 and the constraints in 3.2 can be used to account for both imperfective and nominative pronoun tone shift in Guébie.

\subsection{Tone replacement in noun-noun compounds}

The third instance of morphological tone discussed here involves a tonal overlay, or replacive tone, on the second noun of a genitive noun-noun compound. Noun-noun compounds in Guébie always have an associative, or genitive, meaning. No matter which noun surfaces as the first or second noun in the compound, the tone of the second noun is always replaced with a level 2 tonal melody.

The data in Table 18 shows the lexical tone for a number of Guébie nouns. This is the tone used on nouns in object position, focused position, subject position (except when followed by a tone- 1 imperfective verb), as the object of a postpositional phrase, and as the first noun in a noun-noun compound.

Table 18 Underlying forms

\begin{tabular}{lll}
\hline Noun with underlying tone & Gloss \\
\hline a. & nito $^{3.1}$ & 'fiancé' \\
b. & $\mathrm{ju}^{4}$ & 'child' \\
c. & mana $^{3.3}$ & 'meat' \\
d. & $\mathrm{di}^{3}$ & 'cut' \\
e. & $\mathrm{no}^{31}$ & 'person' \\
f. & bit2 $^{2.3}$ & 'house' \\
g. & wəli $^{3.2}$ & 'top' \\
\hline
\end{tabular}

The data in (43) then shows those same nouns in noun-noun compounds, where the second noun of the compound always has a level tone- 2 melody.

(43) Noun-noun compounds in Guébie
a. nito $^{3.1} \mathrm{ju}^{2}$
fiancé child
'daughter in-law'
b. mana $^{3.3} \mathrm{di}^{2}-\mathrm{no}^{2}$
meat cut-AGT
'butcher'
c. bitə $^{2.3}$ wəli $^{2.2}$
house top
'top of house'

Much like scalar tone shift in the environment of a nominative or imperfective feature, this tonal overlay is analyzed as a phonological change motivated by constraints in 
the environment of a particular morphosyntactic feature. Here the relevant feature is genitive. Unlike the previous cases, the genitive feature does not trigger a scalar process, but a tonal overlay.

To account for this tonal overlay in genitive constructions, we could imagine a genitive-specific phonological grammar that ensures tone replacement of the second noun in the compound. In this genitive-specific grammar, a constraint like the one in (44), in the style of McPherson and Heath's (2016) tone overlay constraints, outranks ID-TONE, ensuring that the second noun of a compound surfaces with tone 2.

\section{Noun Noun ${ }^{2}$}

Assign one violation for every noun immediately following another noun that does not have a level tone melody of 2 .

While there are instances of nouns followed immediately by other nouns in Guébie (indirect and direct objects in ditransitive constructions), the constraint above will be crucially outranked in the elsewhere grammar, and its effects will only apply in the genitive-specific cophonology.

The tonal process seen in Guébie genitive contexts is predicted by Distributed Cophonology Theory plus tonal overlay constraints (McPherson and Heath 2016). We have seen that three distinct instances of tonal morphologically conditioned phonological processes in Guébie can be accounted for with a single model: Phonology has access to morphosyntactic featural information and assigns a phonological grammar to each spell-out domain based on those morphosyntactic features.

\section{Conclusion}

The Guébie imperfective data presented here shows a morphologically conditioned scalar tone shift that scopes over multiple words. I've argued that the Guébie data are best analyzed in Distributed Cophonology Theory, a model of phase-based application of morphology and phonology, where phonological constraint rankings are sensitive to morphosyntactic construction. The specific benefits of the Distributed Cophonology Approach are in 1) accounting for the cross-word effects, and 2) accounting for the lack of consistent realization of the imperfective morpheme.

The cross-word effects of the imperfective morpheme, which can be realized on the subject or following verb, have implications for the domain of phonological evaluation. Morphological and phonological operations must apply to syntactic phases, and not to individual word or sub-word chunks. Word-based theories of phonological evaluation such as Lexical Phonology (Kiparsky 1982) and Stratal OT (BermúdezOtero 1999; Kiparsky 2000, 2008; Bermúdez-Otero in preparation) cannot capture the cross-word effects of the Guébie imperfective scalar tone shift.

Additionally, the Guébie imperfective data has been argued to have implications for purely item-based models. I have shown that morphologically conditioned phonological processes such as Guébie scalar tone shift can be modeled without underlying phonological representations. The availability of morphosyntactic features to the phonological component of grammar is enough to trigger a phonological change in 
the appropriate contexts. This analysis avoids adding additional structure such as tonal root nodes to the model.

The model proposed here takes a theoretical stance on which cross-linguistic phenomena involve phonological processes triggered by morphosyntactic features, as opposed to an alternative such as root suppletion: If a change is phonologically productive, independent of whether it is construction-specific, it involves constraint-driven phonological changes tied to particular cophonologies. In Distributed Cophonology Theory, both affixal and non-affixal morphology are possible in the same theory, and neither is treated as exceptional. This is seen as a benefit, especially in accounting for languages such as Guébie, where morphology is more often exponed via tone shifts and vowel alternations than affixation.

Acknowledgements Thanks to the Guébie community, and especially to Serikpa Emil, Olivier Agodio, Gnakouri, and Sylvain Bodji, who have devoted hours of their time towards this project. Thanks also to Sharon Inkelas, Larry Hyman, Peter Jenks, Darya Kavitskaya, and audiences at MFM, NELS, UC Berkeley, UC Santa Cruz, and Georgetown University for their feedback on various versions of this work. Any errors are my own.

Open Access This article is distributed under the terms of the Creative Commons Attribution 4.0 International License (http://creativecommons.org/licenses/by/4.0/), which permits unrestricted use, distribution, and reproduction in any medium, provided you give appropriate credit to the original author(s) and the source, provide a link to the Creative Commons license, and indicate if changes were made.

\section{References}

Alderete, J. D. (2001). Dominance effects as transderivational anti-faithfulness. Phonology, 18(02), 201253.

Anderson, S. R. (1992). A-morphous morphology. Cambridge: Cambridge University Press.

Anttila, A. (2002). Morphologically conditioned phonological alternations. Natural Language and Linguistic Theory, 20(1), 1-42.

Archangeli, D., \& Pulleyblank, D. (2012). Emergent phonology: Evidence from English. Issues in English linguistics.

Archangeli, D., \& Pulleyblank, D. (2015). Tonal allomorphy in Kinande. In Y. Hsiao \& L. H. Wee (Eds.), Capturing phonological shades within and across languages (pp. 76-100). Cambridge Scholars Publishing.

Archangeli, D., \& Pulleyblank, D. (2016). Emergent morphology. In H. Harley \& S. Daniel (Eds.), Morphological metatheory (pp. 237-270). Amsterdam: Benjamins.

Bao, Z. (1999). The structure of tone. Oxford: Oxford University Press.

Benua, L. (1997). Transderivational identity. PhD thesis, University of Massachusetts, Amherst.

Bermúdez-Otero, R. (1999). Constraint interaction in language change: Quantity in English and Germanic. Manchester: University of Manchester.

Bermúdez-Otero, R. (2012). The architecture of grammar and the division of labour in exponence. In J. Trommer (Ed.), The morphology and phonology of exponence (Vol. 41, pp. 8-83). Oxford: Oxford University Press.

Bermúdez-Otero, R. (in preparation). Stratal optimality theory, Oxford: Oxford University Press.

Bobaljik, J. D. (2000). The ins and outs of contextual allomorphy. University of Maryland Working Papers in Linguistics, 10, 35-71.

Bošković, Ž. (2014). Now I'm a phase, now I'm not a phase: On the variability of phases with extraction and ellipsis. Linguistic Inquiry, 45(1), 27-89.

Bye, P., \& Svenonius, P. (2012). Nonconcatenative morphology as epiphenomenon. In J. Trommer (Ed.), The morphology and phonology of exponence: The state of the art (pp. 427-495). Oxford: Oxford University Press.

Chomsky, N., \& Halle, M. (1968). The sound pattern of English. Pittsburgh: Harper \& Row. 
Clark, M. M. (1978). A dynamic treatment of tone with special attention to the tonal system of Igbo. $\mathrm{PhD}$ thesis, University of New Hampshire.

Clements, G. N. (1983). The hierarchical representation of tone features. Current Approaches to African linguistics, 1, 145-176.

Clements, G. N., Michaud, A., \& Patin, C. (2011). Do we need tone features. In J. A. Goldsmith, E. Hume, \& W. L. Wetzels (Eds.), Tones and features (pp. 3-24). Berlin: De Gruyter Mouton.

Contreras, H. (1969). Simplicity, descriptive adequacy, and binary features. Language, 45, 1-8.

Creissels, D., Dimmendaal, G. J., Frajzyngier, Z., \& König, C. (2008). Africa as a morphosyntactic area. In B. Heine \& D. Nurse (Eds.), A linguistic geography of Africa (pp. 86-150). Cambridge: Cambridge University Press.

d'Alessandro, R., \& Scheer, T. (2015). Modular PIC. Linguistic Inquiry, 46, 593-624.

De Lacy, P. V. (2002). The formal expression of markedness. PhD thesis, University of Massachusetts, Amherst.

Deal, A. R., \& Wolf, M. (2017). Outwards-sensitive phonologically-conditioned allomorphy in Nez Perce. In V. Gribanova \& S. Shih (Eds.), The morphosyntax-phonology connection (pp. 29-60). London: Oxford University Press.

Embick, D. (2010). Localism versus globalism in morphology and phonology (Vol. 60). Cambridge: MIT Press.

Embick, D., \& Halle, M. (2005). On the status of stems in morphological theory. Amsterdam Studies in the Theory and History of Linguistic Science Series, 4(270), 37.

Embick, D., \& Marantz, A. (2008). Architecture and blocking. Linguistic Inquiry, 39(1), 1-53.

Embick, D., \& Noyer, R. (2001). Movement operations after syntax. Linguistic Inquiry, 32(4), 555-595.

Embick, D., \& Noyer, R. (2007). Distributed morphology and the syntax/morphology interface. In: The Oxford handbook of linguistic interfaces (pp. 289-324).

Fitzgerald, C., \& Fountain, A. (1995). The optimal account of Tohono O'Odham truncation. Ms., University of Arizona.

Foley, J. (1970). Phonological distinctive features. Folia Linguistica IV, 1, 87-92.

Fukazawa, H. (1998). Multiple input-output faithfulness relations in Japanese. Ms. University of Maryland, College Park.

Gnanadesikan, A. E. (1997). Phonology with ternary scales. PhD thesis, University of Massachusetts, Amherst.

Gouskova, M., \& Linzen, T. (2015). Morphological conditioning of phonological regularization. The Linguistic Review, 32(3), 427-473.

Gribanova, V. (2015). Exponence and morphosyntactically triggered phonological processes in the Russian verbal complex. Journal of Linguistics, 51(03), 519-561.

Gribanova, V., \& Harizanov, B. (2017). Locality and directionality in inward-sensitive allomorphy: Russian and Bulgarian. In V. Gribanova \& S. Shih (Eds.), The morphosyntax-phonology connection (pp. 61-90). London: Oxford University Press.

Halle, M., \& Marantz, A. (1993). Distributed morphology and the pieces of inflection. In K. Hale \& S. J. Keyser (Eds.), The view from building 20 (pp. 111-176). Cambridge: MIT Press.

Halle, M., \& Marantz, A. (1994). Some key features of Distributed Morphology. MIT Working Papers in Linguistics, 21, 275-288.

Hardy, H. K., \& Montler, T. R. (1988). Imperfective gemination in Alabama. International Journal of American Linguistics, 54(4), 399-415.

Harley, H. (2014). On the identity of roots. Theoretical Linguistics, 40(3-4), 225-276.

Haugen, J. D., \& Siddiqi, D. (2013). Roots and the derivation. Linguistic Inquiry, 44(3), 493-517.

Hockett, C. F. (1954). Two models of grammatical description. Word, 10(2-3), 210-234.

Hyman, L. M. (1988). Underspecification and vowel height transfer in Esimbi. Phonology, 5(02), 255273.

Hyman, L. M. (2010). Do tones have features? In J. A. Goldsmith, E. Hume, \& W. L. Wetzles (Eds.), Tones and features (pp. 50-80). Berlin: Walter de Gruyter.

Hyman, L. M. (2018). Towards a typology of postlexical tonal neutralizations. In H. Kobozono \& M. Giriko (Eds.), Tonal change and neutralization (pp. 7-26). Berlin: De Gruyter Mouton.

Inkelas, S. (2008). The morphology-phonology connection. In Annual meeting of the Berkeley Linguistics Society (Vol. 34, pp. 145-162).

Inkelas, S. (2014). The interplay of morphology and phonology. London: Oxford University Press.

Inkelas, S., \& Zoll, C. (2005). Reduplication: Doubling in morphology (Vol. 106). Cambridge: Cambridge University Press. 
Inkelas, S., \& Zoll, C. (2007). Is grammar dependence real? A comparison between cophonological and indexed constraint approaches to morphologically conditioned phonology. Linguistics, 45(1), 133171.

Inkelas, S., Orgun, O., \& Zoll, C. (1997). The implications of lexical exceptions for the nature of grammar. In J. J. McCarthy (Ed.), Optimality theory in phonology: A reader (pp. 542-551). Oxford: Blackwell.

Itô, J., \& Mester, A. (1995a). The core-periphery structure of the lexicon and constraints on reranking. Papers in Optimality Theory, 18, 181-209.

Itô, J., \& Mester, A. (1995b). Japanese phonology. In J. Goldsmith (Ed.), The handbook of phonological theory (pp. 816-838). Oxford: Blackwell.

Itô, J., \& Mester, A. (1999). Realignment. In R. Kager, H. va der Hulst, \& W. Zonneveld (Eds.), The prosody-morphology interface (pp. 188-217). London: Cambridge University Press.

Jenks, P., \& Rose, S. (2015). Mobile object markers in Moro: The role of tone. Language, 91(2), $269-307$.

Jenks, P., \& Sande, H. (2018). Case and caselessness in Moro. Proceedings of NELS, 47, 109-119.

Kastner, I. (2018). Templatic morphology as an emergent property: Roots and functional heads in Hebrew. Natural Language and Linguistic Theory.

Kiparsky, P. (1982). From cyclic phonology to lexical phonology. In: The structure of phonological representations, part 1 (pp. 131-175).

Kiparsky, P. (2000). Opacity and cyclicity. The Linguistic Review, 17, 351-367.

Kiparsky, P. (2008). Fenno-Swedish quantity: Contrast in Stratal OT. In Rules, constraints, and phonological phenomena. Oxford: Oxford University Press.

Kirchner, R. (1996). Synchronic chain shifts in Optimality Theory. Linguistic Inquiry, 27(2), 341-350.

Kirchner, R. (1997). Contrastiveness and faithfulness. Phonology, 14(01), 83-111.

Köhnlein, B. (2016). When less is more and more is less: Subtractive morphology as prosodic affixation. In: NAPhC9. Montreal.

König, C. (2006). Marked nominative in Africa. Studies in Language (International Journal sponsored by the Foundation "Foundations of Language"), 30(4), 655-732.

Kramer, R. (2010). The Amharic definite marker and the syntax-morphology interface. Syntax, 13(3), 196-240.

Kurisu, K. (2001). The phonology of morpheme realization. PhD thesis, University of California Santa Cruz.

Leben, W. R. (1973). Suprasegmental phonology. PhD thesis, Massachusetts Institute of Technology.

Lieber, R. (1980). On the organization of the lexicon. PhD thesis, Massachusetts Institute of Technology.

Lightner, T. M. (1965). Segmental phonology of modern standard Russian. PhD thesis, Massachusetts Institute of Technology.

Łubowicz, A. (2011). Chain shifts. In: The Blackwell companion to phonology (pp. 1-19).

Marvin, T. (2002). Topics in the stress and syntax of words. PhD thesis, Massachusetts Institute of Technology.

Matushansky, O. (2006). Head movement in linguistic theory. Linguistic Inquiry, 37(1), 69-109.

McCarthy, J. J. (2003). Comparative markedness. Theoretical Linguistics, 29(1-2), 1-51.

McPherson, L. (2016). Cyclic spell-out and the interaction of Seenku tonal processes. Tonal Aspects of Languages (pp. 43-47).

McPherson, L., \& Heath, J. (2016). Phrasal grammatical tone in the Dogon languages. Natural Language and Linguistic Theory, 34(2), 593-639.

Michaels, J. (2013). To alternate or not to alternate: What is the boundary. In Proceedings of 40th meeting of the North East Linguistics Society.

Mortensen, D. R. (2006). Logical and substantive scales in phonology. PhD thesis, University of California, Berkeley.

Newell, H. (2008). Aspects of the morphology and phonology of phases. PhD thesis, McGill University Montreal.

Newman, P. (2000). The Hausa language: An encyclopedic reference grammar. New Haven: Yale University Press.

O'Hara, C. (2017). How abstract is more abstract? Learning abstract underlying representations. Phonology, 34(2), 325-345.

Orgun, C. (1996). Sign-based morphology and phonology with special attention to Optimality Theory. Unpublished dissertation, UC Berkeley.

Padgett, J. (2003). Contrast and post-velar fronting in Russian. Natural Language and Linguistic Theory, 21(1), 39-87. 
Pak, M. (2008). The postsyntactic derivation and its phonological reflexes. PhD thesis, University of Pennsylvania.

Parkinson, F. B. (1996). The representation of vowel height in phonology. PhD thesis, The Ohio State University.

Pater, J. (2007). The locus of exceptionality: Morpheme-specific phonology as constraint indexation. In L. Bateman, M. O’Keefe, E. Reilly, \& A. Werle (Eds.), University of Massachusetts occasional papers (Vol. 32, pp. 259-296). Amherst: GLSA publications.

Pater, J. (2010). Morpheme-specific phonology: Constraint indexation and inconsistency resolution. In S. Parker (Ed.), Phonological argumentation: Essays on evidence and motivation (pp. 123-154). London: Equinox.

Preminger, O. (2011). Agreement as a fallible operation. PhD thesis, Massachusetts Institute of Technology.

Prince, A. (2000). Comparative tableaux. Ms.

Prince, A., \& Smolensky, P. (1993/2004). Optimality Theory: Constraint interaction in generative grammar. Oxford: Blackwell Sci.

Pulleyblank, D. (1986). Tone in lexical phonology (Vol. 4). Berlin: Springer.

Rolle, N. (in preparation). Grammatical tone: Typology, theory, and functional load. $\mathrm{PhD}$ thesis, University of California, Berkeley.

Sande, H. (2016). An interface model of phonologically determined agreement. In Proceedings of the 33rd West coast conference on formal linguistics (pp. 339-350).

Sande, H. (2017a). Distributing morphologically conditioned phonology: Three case studies from Guébie. PhD thesis, UC Berkeley.

Sande, H. (2017b). Phonologically determined agreement in Guébie (pp. 13-51). UC Berkeley Phonology Lab annual report.

Sande, H., \& Jenks, P. (to appear). Cophonologies by phase. In: NELS 48 proceedings.

Selkirk, E. (2009). On clause and intonational phrase in Japanese: The syntactic grounding of prosodic constituent structure. Gengo Kenkyu, 136, 35-73.

Selkirk, E. (2011). The syntax-phonology interface. In J. Goldsmith, J. Riggle, \& A. Yu (Eds.), The handbook of phonological theory (pp. 435-483). Oxford: Blackwell Sci.

Selkirk, E. O. (1982). In The syntax of words, Cambridge, MA.

Shwayder, K. (2015). Words and subwords: Phonology in a piece-based syntactic morphology. PhD thesis, University of Pennsylvania.

Siddiqi, D. (2009). Syntax within the word: Economy, allomorphy, and argument selection in Distributed Morphology (Vol. 138). New York: Benjamins.

Snider, K. (1999). The geometry and features of tone. Dallas: Summer Institute of Linguistics.

Surkalović, D. (2013). Modularity, phase-phase faithfulness, and prosodification of function words in English. In S. Blaho, M. Krämer, \& B. Morén-Duolljá (Eds.), A festschrift on the occasion of x years of CASTL phonology and Curt Rice's Lth birthday (Vol. 40, pp. 301-322). Nordlyd: University of Tromso.

Toosarvandani, M. (2016). Vocabulary insertion and locality: Verb suppletion in Northern Paiute. NELS, 46, 247-256.

Trommer, J., \& Zimmermann, E. (2014). Generalised mora affixation and quantity-manipulating morphology. Phonology, 31(3), 463-510.

Vydrine, V. (2006). Emergence of morphological cases in South Mande. In L. Kulikov, A. Malchukov, \& P. de Swart (Eds.), Case, valency, and transitivity (pp. 49-64). New York: Benjamins.

Walker, R. (1997). Faith and markedness in Esimbi feature transfer. Phonology at Santa Cruz, 5, 103-115.

Winchester, L. (2016). Morphosyntactic features and contextual allomorphy: Evidence from Modern Standard Arabic. NELS, 47, 247-260.

Wolf, M. (2007). For an autosegmental theory of mutation. In University of Massachusetts occasional papers in linguistics (Vol. 32, pp. 315-404).

Yip, M. J. (1980). The tonal phonology of Chinese. PhD thesis, Massachusetts Institute of Technology.

Yu, K., \& Özyildiz, D. (2016). The absolutive ia particle in Samoan. In Proceedings of the 42nd annual meeting of the Berkeley Linguistics Society (pp. 387-406).

Yu, K. M. (2018). Tonal marking of absolutive case in Samoan. Ms.

Zheltov, A. (2005). Le système des marqueurs de personnes en gban: Morphème syncrétique ou syncrétisme des morphèmes? Mandenkan, 41, 23-28.

Zimmermann, E. (2013). Non-concatenative allomorphy is generalized prosodic affixation: The case of Upriver Halkomelem. Lingua, 134, 1-26. 